\title{
The Group I Metabotropic Glutamate Receptor Agonist (S)-3,5- Dihydroxyphenylglycine Induces a Novel Form of Depotentiation in the CA1 Region of the Hippocampus
}

\author{
Wei-Ming Zho, ${ }^{*}$ Jia-Lin You, ${ }^{*}$ Chiung-Chun Huang, and Kuei-Sen Hsu \\ Department of Pharmacology, College of Medicine, National Cheng-Kung University, Tainan 701, Taiwan
}

The ability of activation of group I metabotropic glutamate receptor (mGluR) to induce depotentiation was investigated at Schaffer collateral-CA1 synapses of rat hippocampal slices. Brief bath application (5 min) of group I mGluR agonist (S)-3,5dihydroxyphenylglycine (DHPG) $(10 \mu \mathrm{M})$ induced a long-term depression of synaptic transmission or depotentiation (DEP) of previously established long-term potentiation (LTP), which was independent of NMDA or $A_{1}$ adenosine receptor activation. This DHPG-DEP was observed when DHPG was delivered $3 \mathrm{~min}$ after LTP induction. However, when DHPG was applied at 10 or 30 min after LTP induction, significantly less depotentiation was found. DHPG-DEP (1) is reversible and has the ability to unsaturate LTP, (2) is synapse specific, (3) does not require concurrent synaptic stimulation, (4) is mechanistically distinct from NMDA receptor-dependent depotentiation, (5) requires mGluR5 activation, (6) requires rapamycin-sensitive mRNA translation signaling, (7) does not require phospholipase $\mathrm{C}$ or protein phosphatase activation, and (8) is not associated with a change in paired-pulse (PP) facilitation. In addition, the ability of DHPG to reverse LTP was mimicked by a long train of low-frequency (1 $\mathrm{Hz} / 15$ min) PP stimulation. Moreover, the expression of DHPGDEP is associated with a reduction in the increase of the surface expression of AMPA receptors seen with LTP. These results suggest that the activation of mGluR5 and in turn the triggering of a protein synthesis-dependent internalization of synaptic AMPA receptors may contribute to the DHPG-DEP in the CA1 region of the hippocampus.

Key words: long-term potentiation (LTP); depotentiation; DHPG; metabotropic glutamate receptor (mGluR); AMPA receptor; hippocampus
Activity-dependent modulation of synaptic strength is an important component in the current understanding of the cellular mechanisms underlying learning and memory of the brain (Abraham and Bear, 1996). Much of our understanding of activitydependent synaptic modification and its functional relevance comes from studies on the mammalian hippocampus. In the hippocampus, brief trains of activity can trigger long-lasting increases or decreases in synaptic strength (Bliss and Lømo, 1973; Mulkey and Malenka, 1992; Bliss and Collingridge, 1993; Dudek and Bear, 1993). Although both long-term potentiation (LTP) and long-term depression (LTD) are remarkable for their stability, recent work has shown that they are initially labile and sensitive to disruption by various interfering events or agents. For example, the hippocampal CA1 LTP can be reversed by afferent low-frequency stimulation (LFS) (Barrionuevo et al., 1980; Fujii et al., 1991; O’Dell and Kandel, 1994; Stäubli et al., 1996, 1998; Huang et al., 1999, 2001), episodes of hypoxia (Arai et al., 1990), or pharmacological treatments that interrupt cell-cell or cellmatrix interactions (Bahr et al., 1997), when given shortly after LTP induction. This reversal of synaptic strength from potentiated state to pre-LTP level is referred to as depotentiation (DEP) (Barrionuevo et al., 1980; Fujii et al., 1991; O’Dell and Kandel, 1994; Wagner and Alger, 1996; Huang and Hsu, 2001).

Because LTP, in the mammalian brain, is generally assumed to

Received June 5, 2002; revised July 22, 2002; accepted July 30, 2002.

This work was financially supported by a research grant from the Academic Excellence Program of the Ministry of Education (89-B-FA08-1-4), Taipei, Taiwan.

*W.-M.Z. and J.-L.Y. contributed equally to this work.

Correspondence should be addressed to Dr. Kuei-Sen Hsu, Department of Pharmacology, College of Medicine, National Cheng-Kung University, Tainan 701, Taiwan.E-mail: richard@mail.ncku.edu.tw.

Copyright (c) 2002 Society for Neuroscience $0270-6474 / 02 / 228838-12 \$ 15.00 / 0$ be a synaptic mechanism underlying learning and memory formation (Bliss and Collingridge, 1993), the processes involved in the depression of synaptic potentiation may contribute to the mechanisms of memory loss or forgetting. Although over the past two decades a number of electrical stimulation protocols have been reported to effectively induce depotentiation, none of these protocols have yet been tested for their ability to cause forgetting in behaving animals (Martin et al., 2000). The major problem with doing so is that it is difficult to induce depotentiation on all relevant pathways of the hippocampal formation after an individual learning experience. Moreover, the characterization of the intrinsic pathways involved in behaving learning has been technically difficult. In comparison with electrical stimulation approaches, a pharmacological induction protocol would have the advantage that it is easier to target all of the relevant synapses with a drug and may allow the evaluation of the functional relevance of depotentiation in behaving animals. Thus, the primary goal of this study is to establish a pharmacological depotentiation protocol and to elucidate its induction mechanisms. Here we characterize a group I metabotropic glutamate receptor (mGluR) agonist ( $S$ )-3,5-dihydroxyphenylglycine (DHPG) induction protocol that reliably induces a time-dependent depotentiation at Schaffer collateral-CA1 synapses of rat hippocampal slices. We found that mGluR5 and a rapamycin-sensitive protein synthesis-dependent internalization of AMPA receptors are required for the development of DHPG-induced depotentiation.

\section{MATERIALS AND METHODS \\ Hippocampal slice preparation. Animal care was consistent with the guidelines set by the Laboratory Animal Center of National Cheng-Kung University (NCKU). All experimental procedures were approved by the NCKU Institutional Animal Care and Use Committee. Horizontal hip-}


pocampal slices (400 $\mu \mathrm{m}$ thick) were prepared from 4- to 5-week-old male Sprague Dawley rats after decapitation under halothane anesthesia (Pike et al., 2000). After their preparation, slices were placed in a holding chamber of artificial CSF (ACSF) oxygenated with $95 \% \mathrm{O}_{2}-5 \% \mathrm{CO}_{2}$ and kept at room temperature for at least $1 \mathrm{hr}$ before recording. The composition of the ACSF solution was (in $\mathrm{mm}$ ): $\mathrm{NaCl} 117, \mathrm{KCl} 4.7, \mathrm{CaCl}_{2}$ 2.5, $\mathrm{MgCl}_{2} 1.2, \mathrm{NaHCO}_{3} 25, \mathrm{NaH}_{2} \mathrm{PO}_{4}$ 1.2, and glucose 11 at $\mathrm{pH} 7.3-7.4$, equilibrated with $95 \% \mathrm{O}_{2}-5 \% \mathrm{CO}_{2}$.

Electrophysiological recordings. For the extracellular field potential recordings, a single slice was then transferred to a submerged-type recording chamber and held between two nylon nets. The chamber consisted of a circular well of a low volume (1-2 ml) and was perfused continuously with oxygenated ACSF at a flow rate of $2-3 \mathrm{ml} / \mathrm{min}$ at $32.0 \pm 0.5^{\circ} \mathrm{C}$. Standard extracellular field recording techniques were used (Huang et al., 1999, 2001). Extracellular recordings of field EPSPs (fEPSPs) were obtained from the stratum radiatum using microelectrodes filled with $1 \mathrm{M} \mathrm{NaCl}$ (resistance 2-3 M 2 ). A bipolar stainless steel stimulating electrode was placed in stratum radiatum to activate Schaffer collateral/commissural afferents at $0.033 \mathrm{~Hz}$. The stimulation strength was set to elicit responses equivalent to $30-40 \%$ of the maximal fEPSP. In all experiments, baseline synaptic transmission was monitored for 30 min before drug administration or delivering high-frequency tetanic stimulation (TS). The strength of synaptic transmission was quantified by measuring the slope of fEPSP. The fEPSP slopes were measured from $\sim 20-70 \%$ of the rising phase using a least-squares regression. LTP was induced by high-frequency TS, at the test pulse intensity, consisting of two $1 \mathrm{sec}$ trains of stimuli at $100 \mathrm{~Hz}$, delivered with an interval of $20 \mathrm{sec}$. In some cases, as indicated in Results, depotentiation was induced by application of 15 min paired-pulse low frequency trains of stimuli (PPLFS) (with a $50 \mathrm{msec}$ interstimulus interval) at $1 \mathrm{~Hz}$, and the stimulation intensity was the same as the test pulse intensity. The responses during the trains were not recorded, and for convenience these periods are not shown on the graph. To stimulate independent inputs to the same cell population, two bipolar stimulating electrodes were positioned on both sides of the recording microelectrode, alternating every $15 \mathrm{sec}$. Their positions were arranged so that the same amount of current evoked two responses that did not differ from each other by $>10 \%$. The absence of cross-pathway paired-pulse facilitation (PPF) was used to ensure that the two inputs were independent of each other. The stimulation strength was set to elicit response for which the amplitude was $30-40 \%$ of the maximum spike-free response. All values of residual potentiation reported here were calculated as the changes in fEPSP slope measured 40 min after washout of DHPG. Intracellular recordings were made from CA1 pyramidal cells using glass microelectrodes filled with potassium acetate $(4 \mathrm{M}$ ) having resistances ranging from 60 to $80 \mathrm{M} \Omega$ (Huang et al., 1999). The membrane input resistance of the recording neurons was calculated from the voltage deflection produced by a transient hyperpolarizing current pulse $(0.1 \mathrm{nA}, 80 \mathrm{msec})$ passed through the recording microelectrodes. The EPSP slopes were measured from $\sim 20-70 \%$ of the rising phase using a least-squares regression. Microelectrodes were pulled from microfiber $1.0 \mathrm{~mm}$ capillary tubing on a Brown-Flaming electrode puller (Sutter Instruments, San Rafael, CA). Electrical signals were collected with an Axoclamp-2B (Axon Instruments, Foster, CA) filtered at 1 $\mathrm{kHz}$ and sampled at $10 \mathrm{kHz}$, and an Intel Pentium-based computer with pCLAMP software (Version 7.0; Axon Instruments, Foster City, CA) was used to acquire the data on-line and analyze it off-line.

Biochemical measurements of surface-expressed AMPA receptors. Biotinylation experiments were performed as described previously (Chung et al., 2000). Hippocampal slices were prepared and treated with highfrequency TS with or without DHPG treatment exactly as described in the electrophysiological experiments. At the end of the experiments, the CA1 subregion of the hippocampal slices between the positions of the stimulating and recording electrodes was dissected out and immediately frozen on dry ice. Two to three microdissected CA1 subregions (from control, $50 \mathrm{~min}$ after LTP induction, $42 \mathrm{~min}$ after washout of DHPG with or without previous LTP induction) were pooled together. In each experiment, an entire set of control, LTP, or depotentiation pooled slices was taken from the same animal. The microdissected subregions were then incubated with ACSF containing $1 \mathrm{mg} / \mathrm{ml}$ sulfo-succinimidyl-6(biotinamido) hexanoate (Pierce Chemical Company, Rockford, IL) for $30 \mathrm{~min}$ on ice. Unreacted biotinylation reagent was washed once with ice-cold ACSF and quenched by two successive 20 min washes in ACSF containing $100 \mathrm{~mm}$ glycine, followed by two washes in ice-cold TBS (50 $\mathrm{mm}$ Tris, pH 7.5, $150 \mathrm{~mm} \mathrm{NaCl)}$. The microdissected subregions were lysed in ice-cold homogenate buffer ( $50 \mathrm{~mm}$ Tris-HCl, $100 \mathrm{~mm} \mathrm{NaCl}, 15$
mM sodium pyrophosphate, $50 \mathrm{~mm}$ sodium fluoride, $5 \mathrm{~mm}$ EGTA, $5 \mathrm{~mm}$ EDTA, $1 \mathrm{mM}$ phenylmethylsulfonyl fluoride, 0.5\% Triton X-100, $2 \mathrm{~mm}$ benzamidine, $60 \mu \mathrm{g} / \mathrm{ml}$ aprotinin, and $60 \mu \mathrm{g} / \mathrm{ml}$ leupeptin) and ground with a pellet pestle (Kontes Glassware, Vineland, NJ). Samples were sonicated and spun down at $14,000 \times g$ at $4^{\circ} \mathrm{C}$ for $15 \mathrm{~min}$. Thirty microgram lysates of the resulting supernatant were removed to measure total GluR1, and $90 \mu \mathrm{g}$ lysates of the supernatant was incubated with 100 $\mu \mathrm{l}$ of $50 \%$ Neutravidin agarose (Pierce Chemical Company) for $3 \mathrm{hr}$ at $4^{\circ} \mathrm{C}$ to measure the isolated biotinylated proteins. After the Neutravidin agarose was washed five times with homogenate buffer, bound proteins were eluted with SDS sample buffer by boiling for $15 \mathrm{~min}$. Total protein and isolated biotinylated proteins were analyzed by quantitative immunoblotting with polyclonal anti-GluR1 C-terminal antibody (1:1000, Upstate Biotechnology, Lake Placid, NY). It was then probed with HRPconjugated secondary antibody for $1 \mathrm{hr}$ and developed using the ECL immunoblotting detection system. Immunoblots were quantified by densitometric measurement using BioLight software.

Drug application. All drugs were applied by dissolving them to the desired final concentrations in the ACSF and by switching the perfusion from control ACSF to drug-containing ACSF. Appropriate stock solutions of drugs were made and diluted with ACSF just before application. 8-Cyclopentyl-1,3-dipropylxanthine (DPCPX), cycloheximide, anisomycin, actinomycin D, rapamycin, FK506, and U73122 were dissolved in dimethylsulfoxide (DMSO) stock solutions and stored at $-20^{\circ} \mathrm{C}$ until the day of experiment. The concentration of DMSO in the perfusion medium was $0.05 \%$, which alone had no effect on the induction of either LTP or DHPG-induced depotentiation in the CA1 region of rat hippocampus. LY341495 and LY367385 were prepared by first dissolving them in an equimolar amount of $\mathrm{NaOH}$ as a concentrated stock solution and then diluting to their final concentration in ACSF. DHPG, 2-methyl-6-(phenylethynyl)pyridine (MPEP), D(-)-2-amino-5-phosphonopentanoic acid (DAPV), cycloheximide, anisomycin, actinomycin D, rapamycin, U73122, and okadaic acid were purchased from Tocris Cookson Ltd. (Bristol, UK); FK506 was purchased from Calbiochem (La Jolla, CA).

Statistical analysis. The data for each experiment were normalized relative to baseline. Data are presented as mean \pm SEM. The significance of the difference between the mean was calculated by a paired or unpaired Student's $t$ test as appropriate. Numbers of experiments are indicated by $n$. Probability values of $p<0.05$ were considered to represent significant differences.

\section{RESULTS}

\section{Brief bath application of group I mGluR agonist DHPG causes synaptic depression}

Consistent with previous studies (Palmer et al., 1997; Huber et al., 2000, 2001), application of group I mGluR agonist DHPG $(1-50 \mu \mathrm{M})$ for $5 \mathrm{~min}$ caused an acute, dose-dependent reduction of field potentials (Fig. 1A). At concentrations $\geq 10 \mu \mathrm{M}$, the fEPSP did not fully recover after washout of drug. Instead, the synaptic response remained at a depressed level $(10 \mu \mathrm{M}$ : $87.6 \pm$ $5.7 \%$ of pre-DHPG baseline; $n=7 ; 20 \mu \mathrm{M}: 76.8 \pm 4.7 \% ; n=8$; $50 \mu \mathrm{M}: 62.5 \pm 5.6 \% ; n=5$; measured at $30 \mathrm{~min}$ after DHPG washout). This DHPG-induced long-term synaptic depression was also confirmed by intracellular recordings. As shown in Figure $1 B$, DHPG $(10 \mu \mathrm{M})$ application resulted in an initial large reduction of EPSP followed by a slow recovery, but the EPSPs remained at a depressed level after washout of the drug (86.8 \pm $4.7 \%$ of pre-DHPG baseline; $n=5$ ). Although DHPG application also produced a transient membrane depolarization from $-71.5 \pm 2.2$ to $-63.5 \pm 2.1 \mathrm{mV}(n=5 ; p<0.05$; paired Student's $t$ test) that was accompanied by a increase in membrane input resistance from $48.6 \pm 2.6$ to $56.8 \pm 2.3 \mathrm{M} \Omega(n=5 ; p<0.05$; paired Student's $t$ test), these changes were not long lasting and did not correlate with the change in EPSPs. At $30 \mathrm{~min}$ after DHPG washout, the resting membrane potential and membrane input resistance were $-71.2 \pm 2.7 \mathrm{mV}$ and $47.8 \pm 2.6 \mathrm{M} \Omega$, respectively, which were not significantly different from those found during the control baseline period $(p>0.05$; paired Student's $t$ test). Thus, DHPG-induced long-term synaptic de- 
A

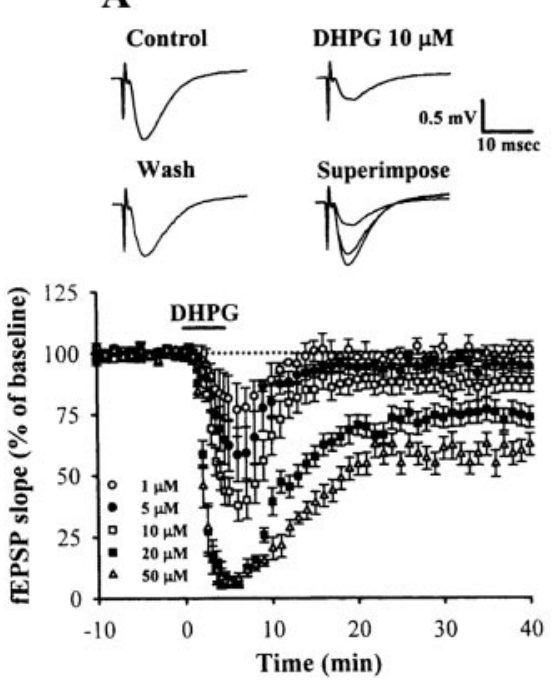

B

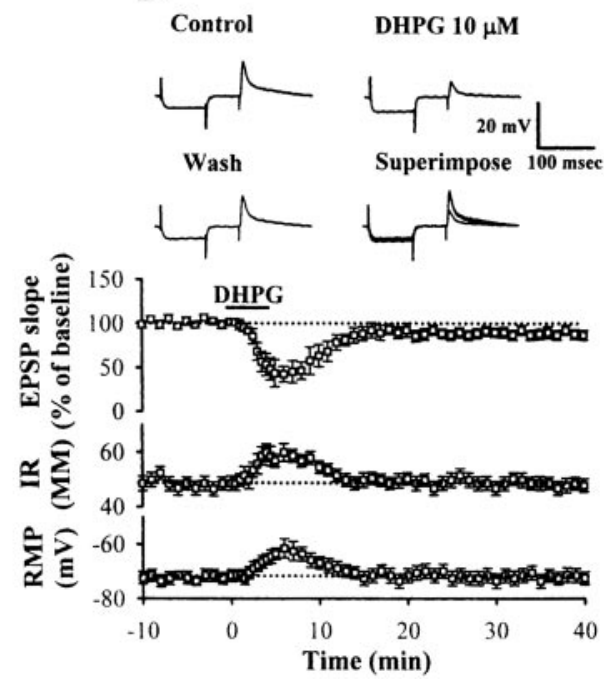

Figure 1. Effects of DHPG on EPSPs. A, A brief application of DHPG for 5 min produced an acute, dose-dependent depression of extracellular fEPSP. At concentrations $\geq 10 \mu \mathrm{M}$, the fEPSPs did not fully recover after washout of drug. Example traces in the top portion are taken from a slice treated with $10 \mu \mathrm{M}$ DHPG. $B$, Summary of experiments $(n=5)$ showing that DHPG $(10 \mu \mathrm{M} ; 5 \mathrm{~min})$ application caused a persistent depression of intracellular EPSP. Although DHPG application also produced a transient membrane depolarization and an increase in membrane input resistance, these changes are not long lasting and did not correlate with the change of EPSPs. Example traces in the top portion are taken from a slice treated with $10 \mu \mathrm{M}$ DHPG. pression seems not to be a mere reflection of the change of membrane excitability of CA1 pyramidal neurons after DHPG treatment. Because a 5 min application of $10 \mu \mathrm{M}$ DHPG consistently produced a long-lasting synaptic depression without significant long-term changes in neuronal excitability, we chose this protocol to examine the role of group I mGluRs in the induction of depotentiation at Schaffer collateral-CA1 synapses.

\section{DHPG induces depotentiation}

Having confirmed the existence of a DHPG-induced LTD (DHPG-LTD) at Schaffer collateral-CA1 synapses, we next asked whether the activation of group I mGluRs by DHPG can trigger depotentiation. We initially confirmed that our $100 \mathrm{~Hz}$ tetanization protocol reliably induced robust LTP, similar to that reported previously (Fig. 2A) (Huang et al., 1999, 2001). The slope of the fEPSP measured 50 min after high-frequency TS was $153 \pm 12 \%(n=8)$ of baseline (Fig. $2 B)$. We next examined the effect of a brief $(5 \mathrm{~min})$ application of DHPG $(10 \mu \mathrm{M})$ on the previously established LTP. As expected, DHPG applied $3 \mathrm{~min}$ after LTP induction exerted a significant suppression of fEPSPs. After washout of DHPG, the fEPSP recovered to near the pretetanus baseline (Fig. $2 C$ ). On average, the fEPSP slope measured 40 min after washout of DHPG was $105 \pm 10 \%(n=6)$ of baseline (Fig. 2D). In contrast, when DHPG was applied 10 or 30 min after LTP induction, the magnitude of depotentiation was reduced markedly (Fig. $2 E, G$ ). The mean residual potentiation measured 40 min after DHPG washout was $136.8 \pm 8.8 \%(n=6)$ and $138 \pm 11 \%(n=6)$ of baseline, respectively (Fig. $2 F, H)$. Comparison of the effect of DHPG applied to naive synapses (DHPG-LTD) or applied 3, 10, or 30 min after LTP induction was summarized in Figure 2I, in which the magnitude of depression measured 40 min after washout of DHPG was calculated relative to the baseline just before DHPG application. The magnitude of depotentiation in which DHPG was applied 3 min after LTP induction was calculated by comparing the synaptic responses at $40 \mathrm{~min}$ from the experiments illustrated in Figure $2 D$ with the magnitude of LTP at $48 \mathrm{~min}$ from the experiments illustrated in Figure $2 B$. As shown in Figure $2 I$, the magnitude of depotentiation in which DHPG was given 3 min $(41.5 \%)$ after LTP was significantly larger than the LTD elicited at naive synapses $(13.2 \pm 4.7 \% ; p<0.05$; unpaired Student's $t$ test). However, when DHPG was given 10 or 30 min after LTP induc- tion, the magnitude of depotentiation was the same as for LTD at naive synapses $(14.3 \pm 9.4$ and $16.2 \pm 8.9 \%$, respectively, versus $13.2 \pm 4.7 \% ; p>0.05$; unpaired Student's $t$ test). These results suggest that hippocampal CA1 LTP is vulnerable to disruption by DHPG application within a brief period after its induction.

\section{Induction of DHPG-DEP unsaturates LTP}

Having confirmed the existence of a time-dependent reversal of LTP by brief application of DHPG (DHPG-DEP) at Schaffer collateral-CA1 synapses, we next examined whether the synapses that had undergone depotentiation could subsequently exhibit LTP. We adopted the approach used to address the same question after the induction of homosynaptic LTD at these synapses (Dudek and Bear, 1993; Mulkey et al., 1993). As shown in Figure $3 A$, high-frequency TS led to LTP that stabilized at a value of $159 \pm 11 \%$ (30 min after TS; $n=8 ; p<0.05$; paired Student's $t$ test) of baseline. In control experiments, application of a second TS delivered $30 \mathrm{~min}$ later resulted in only $13.6 \pm 8.1 \%$ additional LTP ( $n=8 ; p<0.05$; paired Student's $t$ test). Figure $3 B$ illustrates the experiments that were identical to those in Figure $3 A$, with the only difference that DHPG $(10 \mu \mathrm{M})$ was delivered 3 min after the first TS. The second TS that followed DHPG washout caused significantly more LTP than in control experiments $(P<0.05$; unpaired Student's $t$ test) (Fig. $3 B, C)$. A second TS 30 min later caused the fEPSP amplitude to increase by $58.5 \pm$ 9.4\% $(n=8)$ of baseline. These results suggest that DHPG-DEP is reversible and has the ability to unsaturate LTP.

\section{DHPG-DEP is synapse specific}

The following experiment was designed to investigate whether DHPG-DEP is synapse specific. To address this question, two stimulating electrodes were placed on both sides of the recording microelectrode in the CA1 region to activate two groups of synapses to the same dendritic field. As a typical example illustrated in Figure $4 A$, independence of inputs activated by the two electrodes was assessed by verifying the absence of heterosynaptic facilitation between the two inputs using paired stimuli applied at $40 \mathrm{msec}$ intervals. By having confirmed the independence of afferents activated, we then induced LTP at the synapses of one input (test pathway) by giving a high-frequency tetanic stimulation; this was followed by a brief application of DHPG $(10 \mu \mathrm{M})$. Application of the high-frequency tetanic stimulation to the test 

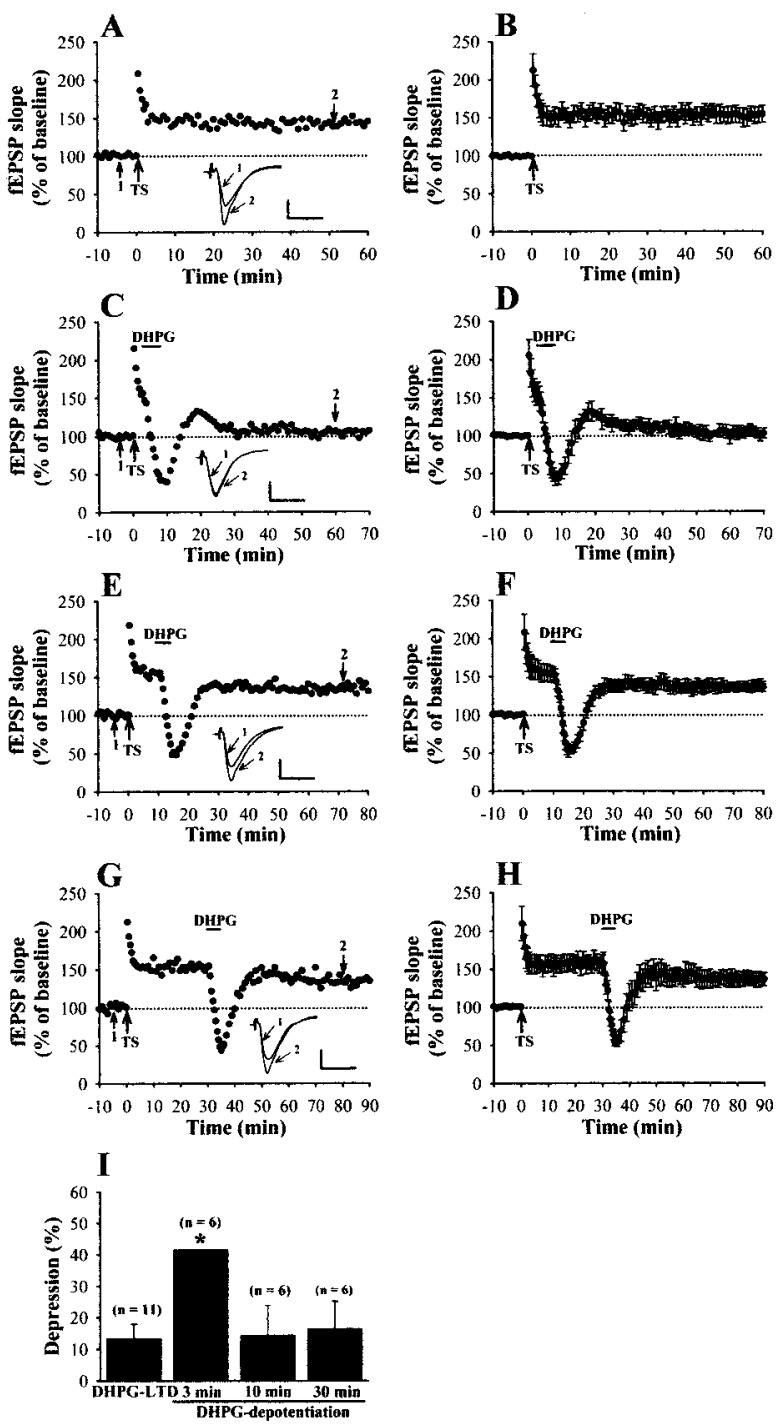

Figure 2. DHPG induces a time-dependent reversal of LTP. A, An example of the time course and magnitude of CA1 LTP. High-frequency TS to the Schaffer collateral afferent fibers resulted in a large post-tetanic potentiation lasting for several minutes after TS, followed by stable LTP expression. $B$, Summary of data from eight experiments performed as in $A$. $C, E, G$, Examples in which DHPG (10 $\mu \mathrm{M} ; 5$ min) was applied at various times after LTP induction: $C, 3$ min after; $E, 10$ min after; $G, 30$ min after. $D, F, H$, Summary of experiments similar to those shown in $C$, $E$, and $G$. I, Histogram comparing the effect of DHPG applied to naive synapses (DHPG-LTD) or applied 3, 10, or $30 \mathrm{~min}$ after LTP induction. The magnitude of DHPG-LTD was calculated at $40 \mathrm{~min}$ after washout of DHPG at naive synapses. The magnitude of 3 min delay depotentiation was calculated by comparing the synaptic responses at $40 \mathrm{~min}$ after washout of DHPG from the experiments illustrated in $D$ with the magnitude of LTP at 48 min from the experiments illustrated in $B$. Because both sets of data have variance, it is not possible to calculate an SE of this depotentiation value. Statistical analysis using ANOVA indicates that this value is significantly different from LTP at naive synapses $(* p<0.05)$. The magnitude of 10 and 30 min delay depotentiation was calculated by comparing the synaptic responses at $40 \mathrm{~min}$ after washout of DHPG from the experiments illustrated in $F$ or $H$ with the individual baseline magnitude just before each DHPG application. Note that DHPG erased potentiation when delivered 3 min after TS but was without effect when applied 10 or $30 \mathrm{~min}$ after. The superimposed fEPSP in the inset illustrates respective recordings from example experiments taken at the time indicated by number. Horizontal bars denote the period of the delivery of DHPG. Calibration: $0.5 \mathrm{mV}, 10 \mathrm{msec}$.
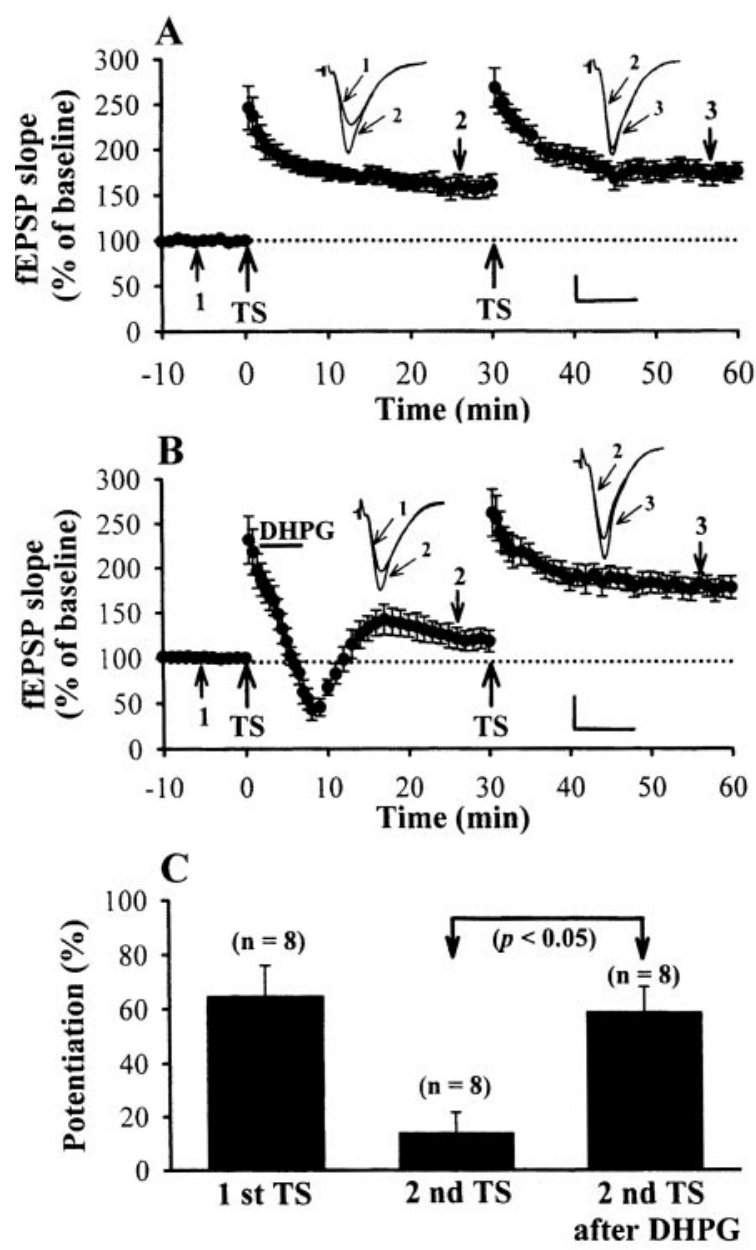

Figure 3. The depressed synapses can be potentiated. $A$, Summary of eight experiments in which TS was applied twice with a 30 min interval. $B$, Summary of eight experiments identical to those shown in $A$ with the exception that DHPG (10 $\mu \mathrm{M} ; 5 \mathrm{~min})$ was delivered 3 min after the first TS. In this case, subsequent TS 30 min later was able to reverse the synaptic depression caused by DHPG. $C$, Summary data in which the magnitude of the potentiation measured $30 \mathrm{~min}$ after each TS was calculated relative to the baseline period before each TS was applied. In control experiments, as illustrated in $A$, we found that the first TS produced a potentiation of $65 \pm 12 \%$ above baseline, whereas the second TS produced an additional increase of only $13.6 \pm 7.8 \%$. In the experiments as shown in $B$, in which the second TS followed a brief DHPG application, it caused a potentiation of $58.5 \pm 9.4 \%$ above baseline $(p<0.05)$. Calibration: $0.2 \mathrm{mV}, 10 \mathrm{msec}$.

pathway generated homosynaptic LTP without noticeable modifications of the control, naive pathway. When DHPG was applied 3 min after LTP induction, LTP was reversed almost completely. The mean residual potentiation measured $40 \mathrm{~min}$ after washout of DHPG was $115.3 \pm 7.9 \%(n=6)$ of baseline. At the control pathway, the mean residual synaptic response measured $40 \mathrm{~min}$ after washout of DHPG was $86.8 \pm 5.6 \%(n=6)$ of pre-DHPG baseline, which was not significantly different from that found in slices without receiving tetanic stimulation $(87.7 \pm 5.7 \% ; n=7)$ (Fig. 1A). These results indicated that tetanizing of one pathway does not affect the DHPG-mediated synaptic depression in the untetanized pathway. Therefore, DHPG-DEP at Schaffer collateral-CA1 synapses is a synapse-specific phenomenon. 


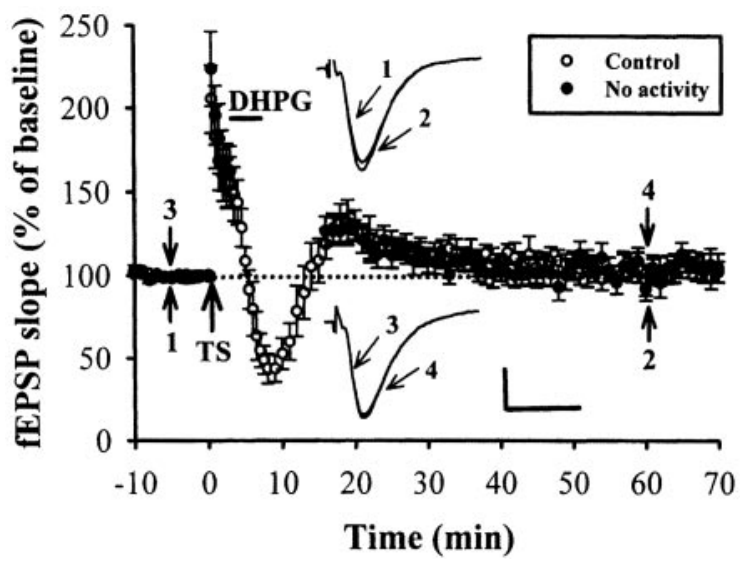

Figure 4. DHPG-induced depotentiation does not require concurrent synaptic stimulation: summary graph of six experiments. Two stimulatory electrodes were used to activate two independent groups of afferents (confirmed by no heterosynaptic facilitation). After a stable baseline was established, LTP was induced on two afferent pathways by coactivation, followed by application of DHPG $(10 \mu \mathrm{M} ; 5 \mathrm{~min})$. In the test pathway, the stimulation was stopped during the application of DHPG and did not restart stimulation until 10 min after the washout of DHPG. Depotentiation was successfully induced in both control and test stimulation pathways. The superimposed fEPSP in the inset illustrates respective recordings from example experiments taken at the time indicated by number. Horizontal bars denote the period of the delivery of DHPG. Calibration: $0.5 \mathrm{mV}, 10 \mathrm{msec}$.

\section{Concurrent synaptic stimulation is not required for DHPG-DEP}

In all of above experiments, synaptic stimulation was administered throughout the application of DHPG, and it cannot be concluded that group I mGluR activation alone is sufficient to induce depotentiation. To determine whether concurrent synaptic stimulation is necessary for the triggering DHPG-DEP, two independent pathways converging into the same postsynaptic population of CA1 neurons were stimulated. After a stable baseline was established for the two pathways, LTP was induced by high-frequency TS to both pathways simultaneously. This was followed by a brief bath application of DHPG to reverse LTP. In the control pathway, synaptic transmission was monitored throughout the application of DHPG, whereas the afferent stimulation in the test pathway was terminated as soon as DHPG was applied, and the stimulation was restarted $10 \mathrm{~min}$ after washout of DHPG. In the test pathway, absence of stimulation during DHPG application was still able to reverse LTP. The average fEPSP amplitude measured 40 min after washout of DHPG was $103.4 \pm$ $8.5 \%(n=6)$ of baseline, which was not significantly different from that measured in the control pathway $(105.7 \pm 8.6 \%$ of baseline; $p>0.05$; paired Student's $t$ test) (Fig. 5). Thus, activation of group I mGluRs alone is sufficient to induce depotentiation without concurrent synaptic stimulation.

\section{mGluR5 mediates DHPG-DEP}

Because group I mGluRs include mGluR1 and mGluR5 subtypes (Anwyl, 1999), both of which are activated by DHPG, we next examined which group I mGluR subtype mediates the DHPGDEP. To address this issue, we performed a series of experiments in which we analyzed the effect of mGluR antagonists on the development of DHPG-DEP. Figure 6 summarizes our pharmacological examination of DHPG-DEP. Initially, we examined the effect of the broad-spectrum mGluR antagonist LY341495 (10

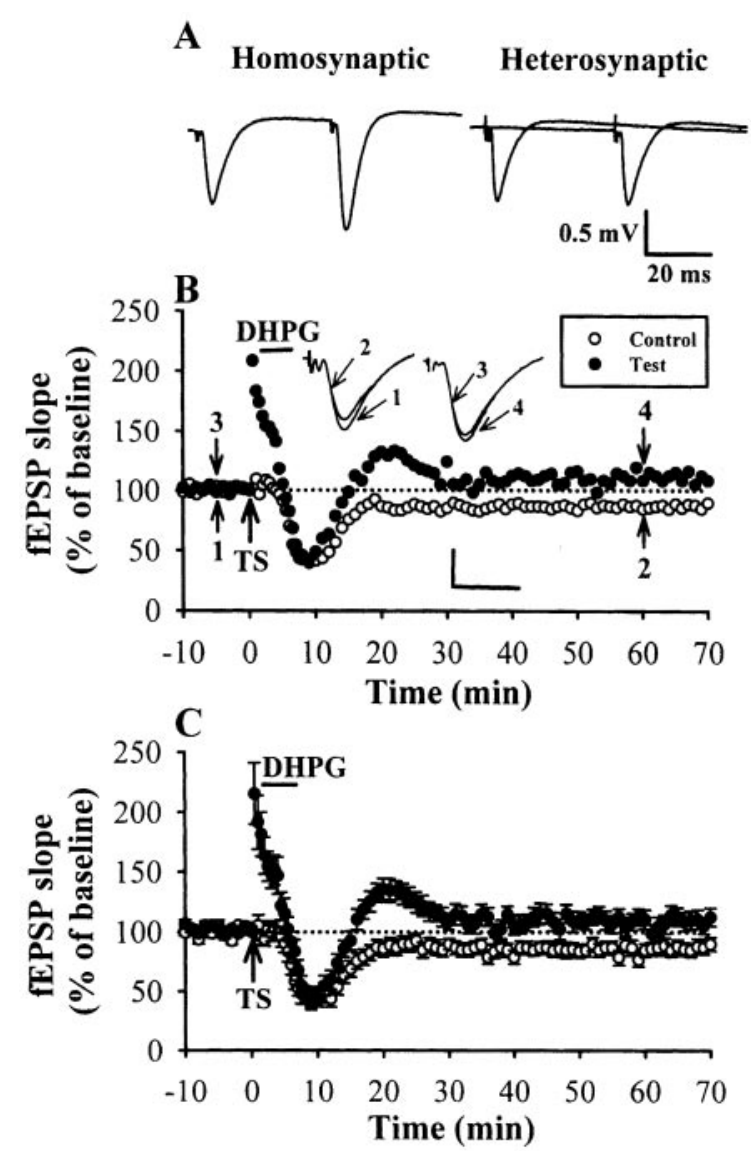

Figure 5. DHPG-DEP is synapse specific. $A$, An example showing that two stimulating electrodes were used to activate two independent groups of afferents. Field EPSPs were evoked by paired stimulations applied at 40 msec intervals to the first or second afferent, or both. Paired-pulse facilitation was present when stimuli were applied twice to the same afferent (homosynaptic facilitation) but not when the stimuli were applied to different afferents (no heterosynaptic facilitation). $B$, Example of an experiment showing that two pathways were recorded simultaneously and LTP was induced only in the test pathway. Application of DHPG after the induction of LTP reverses the enhancement. The superimposed fEPSP in the inset illustrates respective recordings from example experiments taken at the time indicated by number. Horizontal bars denote the period of the delivery of DHPG. Calibration: $0.5 \mathrm{mV}, 10 \mathrm{msec}$. $C$, Summary of data from six experiments performed as in $B$.

$\mu \mathrm{M})$ on DHPG-DEP. As shown in Figure 6A, when LY341495 was applied during DHPG application, both the acute response and the resulting depotentiation were inhibited significantly ( $p<$ 0.05 ; unpaired Student's $t$ test). The mean residual potentiation measured 40 min after DHPG washout was $154 \pm 11 \%(n=8)$ of baseline. We next tested the effect of the highly selective mGluR1 antagonist LY367385 $(100 \mu \mathrm{M})$ on the DHPG-DEP. Although LY367385 exerted a partial but significant reduction of the acute response during DHPG application ( $p<0.05$; unpaired Student's $t$ test), it did not affect the magnitude of DHPG-DEP ( $p>$ 0.05 ; unpaired Student's $t$ test). The mean residual potentiation measured 40 min after DHPG washout was $108.9 \pm 7.8 \%(n=6)$ of baseline (Fig. 6B). Finally, we examined the effect of the selective mGluR5 antagonist MPEP $(10 \mu \mathrm{M})$ on the DHPG-DEP. As shown in Figure $6 C$, MPEP also produced a partial but significant reduction of the acute response during DHPG application ( $p<0.05$; unpaired Student's $t$ test) and completely prevented the induction of DHPG-DEP $(p<0.05$; unpaired 

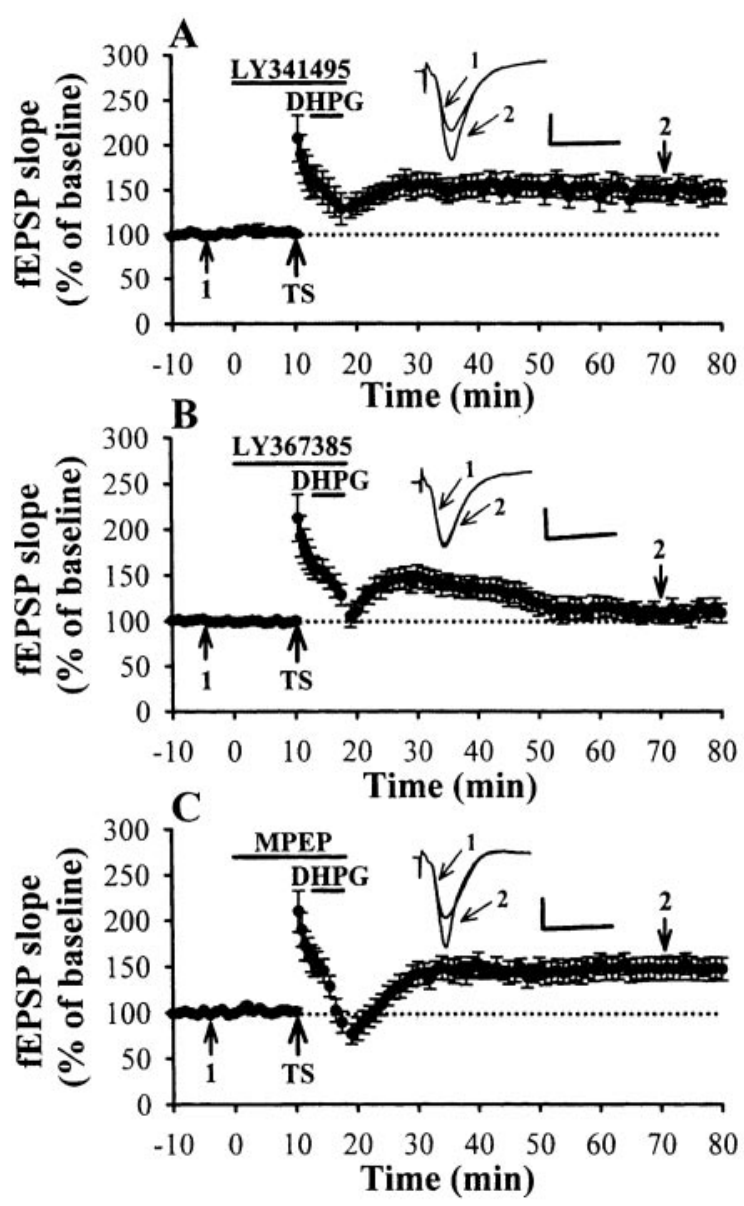

Figure 6. Application of mGluR5 antagonist selectively prevents the induction of DHPG-DEP. $A$, Summary of eight experiments in which broad-spectrum mGluR antagonist LY341495 $(10 \mu \mathrm{M})$ was applied $10 \mathrm{~min}$ before and left until the end of DHPG application (10 $\mu \mathrm{M} ; 5 \mathrm{~min})$. Both the acute response and the resulting depotentiation induced by DHPG were effectively blocked by LY341495. B, Summary of six experiments showing that the selective mGluR1 antagonist LY367385 $(100 \mu \mathrm{M})$ did not affect DHPG-DEP, although it can partially inhibit the acute synaptic depression by DHPG. $C$, Summary of eight experiments showing that the induction of DHPG-DEP was inhibited by a selective mGluR5 antagonist MPEP $(10 \mu \mathrm{M})$. The superimposed fEPSP in the inset illustrates respective recordings from example experiments taken at the time indicated by number. Horizontal bars denote the period of delivery of DHPG or mGluR antagonists as indicated. Calibration: $0.5 \mathrm{mV}, 10 \mathrm{msec}$.

Student's $t$ test). The mean residual potentiation measured $40 \mathrm{~min}$ after DHPG washout was $149 \pm 11 \%(n=8)$ of baseline. These results suggest that the activation of the mGluR5 subtype is an absolute requirement for the induction of DHPG-DEP at Schaffer collateral-CA1 synapses.

\section{NMDA and $A_{1}$ adenosine receptor activation are not required for DHPG-DEP}

We and other groups (Larson et al., 1993; O’Dell and Kandel, 1994; Stäubli and Chun, 1996; Fujii et al., 1997; Huang et al., 1999, 2001) have shown previously that the induction of depotentiation by LFS at Schaffer collateral-CA1 synapses is dependent on the activation of NMDA and $A_{1}$ adenosine receptors. It was therefore of interest to examine the role of NMDA and $\mathrm{A}_{1}$ adenosine receptor activation in the development of DHPG-DEP. If activation of these receptors is critical for DHPG-DEP, their blockade should inhibit the induction of DHPG-DEP. To test this idea, we
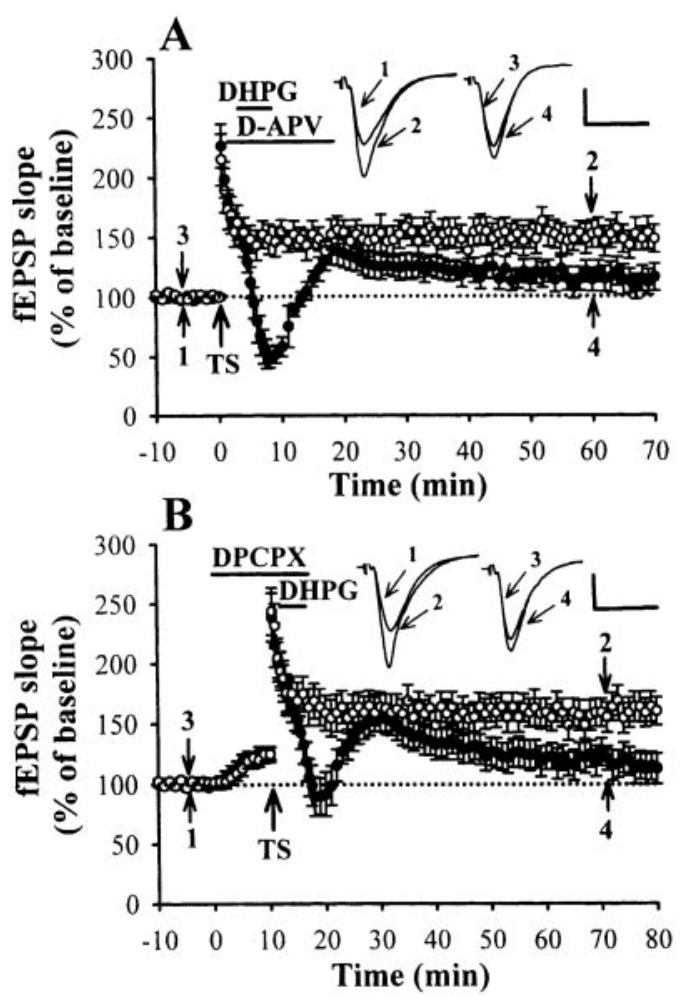

Figure 7. NMDA and $\mathrm{A}_{1}$ adenosine receptor activation are not required for DHPG-DEP. $A$, Summary of experiments showing that neither DHPG-DEP $(n=6)$ nor LTP $(n=5)$ was affected by the NMDA receptor antagonist D-APV $(25 \mu \mathrm{M})$ that had been applied immediately after tetanic stimulation $(T S)$. $B$, Summary of experiments showing that $\mathrm{A}_{1}$ adenosine receptor antagonist DPCPX $(1 \mu \mathrm{M})$ did not affect the induction of LTP $(n=5)$ or DHPG-DEP $(n=6)$. The superimposed fEPSP in the inset illustrates respective recordings from example experiments taken at the time indicated by number. Horizontal bars denote the period of the delivery of DHPG, D-APV, or DPCPX as indicated. Calibration: $0.5 \mathrm{mV}, 10 \mathrm{msec}$.

examined the effect of the NMDA receptor antagonist D-APV (25 $\mu \mathrm{M})$ and $\mathrm{A}_{1}$ adenosine receptor antagonist DPCPX $(1 \mu \mathrm{M})$ on the development of DHPG-DEP. We found that the induction of DHPG-DEP was not significantly affected by either D-APV or DPCPX pretreatment (Fig. 7). On average, the residual potentiation measured $40 \mathrm{~min}$ after DHPG washout was $115.5 \pm 8.2 \%$ ( $n=6 ; p>0.05$ when compared with control DHPG-DEP slices; unpaired Student's $t$ test $)$ and $119 \pm 12 \%(n=6 ; p>0.05$ when compared with control DHPG-DEP slices; unpaired Student's $t$ test) of baseline, respectively. Moreover, the induction of LTP was not significantly affected by either D-APV or DPCPX treatment. The slope of the fEPSP measured $50 \mathrm{~min}$ after LTP induction was $153 \pm 11 \%(n=5 ; p>0.05$ when compared with control LTP slices; unpaired Student's $t$ test) and $158 \pm 12 \%(n=$ $5 ; p>0.05$ when compared with control LTP slices; unpaired Student's $t$ test) of baseline, respectively (Fig. 7). These results suggest that the induction of DHPG-DEP is not attributable to the activation of either NMDA or $\mathrm{A}_{1}$ adenosine receptors.

\section{PLC signaling is not required for DHPG-DEP}

Because mGluR5 is coupled to $\mathrm{G}_{\mathrm{q}}$-protein, which activates PLC and therefore can activate phosphoinositide hydrolysis (Anwyl, 1999), we explored the possibility that an mGluR5-mediated activation of PLC is essential for triggering DHPG-DEP. To test this idea, we directly examined the effect of U73122, a broad- 


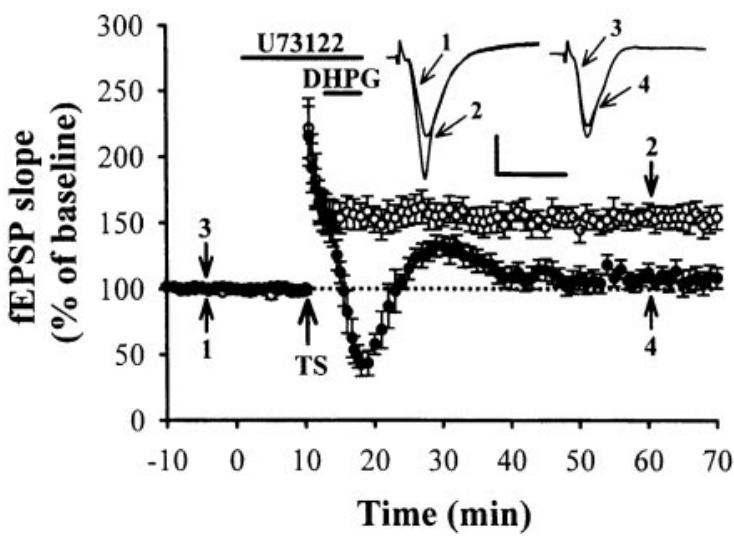

Figure 8. DHPG-DEP is independent of the PLC signaling pathway. Shown is a summary of experiments $(n=6)$ in which a broad-spectrum PLC blocker U73122 (10 $\mu \mathrm{M})$ was applied previous to the application of TS and DHPG (10 $\mu \mathrm{M} ; 5 \mathrm{~min})$. Note that U73122 had no consistent effect on the induction of either LTP or DHPG-DEP. The superimposed fEPSP in the inset illustrates respective recordings from example experiments taken at the time indicated by number. Horizontal bars denote the period of the delivery of DHPG or U73122. Calibration: $0.5 \mathrm{mV}, 10 \mathrm{msec}$.

spectrum PLC blocker, on the induction of DHPG-DEP. A recent study has reported that U73122, when applied at a dose of $10 \mu \mathrm{M}$, specifically blocked PLC $\beta 1$-dependent cationic conductance elicited by DHPG in the hippocampal CA3 neurons (Chuang et al., 2001). We therefore examined this dose of U73122 on the induction of DHPG-DEP. As shown in Figure 8, application of U73122 $(10 \mu \mathrm{M})$ alone failed to affect the LTP induction and did not affect the degree of DHPG-DEP. The slope of fEPSP measured $50 \mathrm{~min}$ after LTP induction was $152.6 \pm 8.2 \%(n=6 ; p>0.05$ when compared with control slices; unpaired Student's $t$ test) of baseline. Moreover, the residual potentiation measured $40 \mathrm{~min}$ after DHPG washout was $107.3 \pm 7.2 \%(n=7 ; p>0.05$ when compared with control DHPG-DEP slices; unpaired Student's $t$ test). These results indicate that mGluR5-mediated DHPG-DEP is not attributable to the activation of PLC signaling.

\section{Protein phosphatase activation is not required for DHPG-DEP}

Because hippocampal CA1 LTP is generally thought to be caused, at least in part, by the activation of several postsynaptic protein kinases, including $\mathrm{Ca}^{2+} /$ calmodulin-dependent protein kinase II, protein kinase $\mathrm{C}(\mathrm{PKC})$, mitogen-activated protein kinase, protein kinase A, and Src family protein tyrosine kinases (Bliss and Collingridge, 1993; Malenka and Nicoll, 1999; Sanes and Lichtman, 1999), it is therefore reasonable to suggest that DHPG may elicit depotentiation by interfering with the protein phosphorylation processes required for LTP, perhaps by activating PPcoupled cascades. This proposal was supported by our previous observation showing that pretreatment of the hippocampal slices with serine/threonine-PP inhibitors, okadaic acid or calyculin A, prevents the LFS-induced depotentiation at Schaffer collaterCA1 synapses (Huang et al., 1999, 2001). If PP is critical for DHPG-DEP, blockade of PP activity should inhibit the induction of depotentiation by DHPG. To test this idea, we examined the effect of potent PP1/2A inhibitors, okadaic acid and calyculin A, on the development of DHPG-DEP. We found that the degree of DHPG-DEP was not significantly affected by a 2-4 hr preincubation of hippocampal slices with either okadaic acid $(1 \mu \mathrm{M})$ or calyculin A $(1 \mu \mathrm{M})$. On average, the residual potentiation mea- sured 40 min after washout of DHPG was $112.7 \pm 8.6 \%(n=6$; $p>0.05$ when compared with control DHPG-DEP slices; unpaired Student's $t$ test) and $109.5 \pm 7.9 \%(n=6 ; p>0.05$ when compared with control DHPG-DEP slices; unpaired Student's $t$ test) of baseline, respectively (Table 1). Moreover, these treatments alone failed to affect the LTP induction. The fEPSP slope measured 50 min after LTP induction was $165 \pm 11 \%(n=5 ; p>$ 0.05 when compared with control LTP slices; unpaired Student's $t$ test $)$ and $162.6 \pm 9.1 \%(n=5 ; p>0.05$ when compared with control LTP slices; unpaired Student's $t$ test) of baseline, respectively (Table 1).

To examine the possible contribution of PP2B (calcineurin) to depotentiation, slices were preincubated for 2-4 hr in FK506 (10 $\mu \mathrm{M})$. We found that FK506 possessed no significant effect on DHPG-DEP; the degree of depotentiation did not differ from the control slices. The mean residual potentiation measured $40 \mathrm{~min}$ after washout of DHPG was $112.6 \pm 9.3 \%(n=5 ; p>0.05$ when compared with control DHPG-DEP slices; unpaired Student's $t$ test) of baseline (Table 1, Fig. 9B). Pretreatment of the slices with another inhibitor of PP2B, cyclosporin A (250 $\mu \mathrm{M})$, was similarly ineffective on DHPG-DEP. On average, the residual measured 40 min after washout of DHPG was $116 \pm 11 \%(n=4 ; p>0.05$ when compared with control DHPG-DEP slices; unpaired Student's $t$ test) of baseline (Table 1). Additionally, the induction of LTP was not significantly affected by either F K506 or cyclosporin A pretreatment. The slope of the fEPSP measured 50 min after LTP induction was $152.3 \pm 9.4 \%(n=5 ; p>0.05$ when compared with control LTP slices; unpaired Student's $t$ test) and $158.8 \pm$ $8.9 \%(n=6 ; p>0.05$ when compared with control LTP slices; unpaired Student's $t$ test) of baseline, respectively (Table 1). These results suggest that the induction of DHPG-DEP does not require the activation of $\mathrm{PP} 1 / 2 \mathrm{~A}$ or $\mathrm{PP} 2 \mathrm{~B}$.

\section{DHPG-DEP requires rapamycin-sensitive mRNA translation signaling}

Previous studies have shown that a rapid synthesis of dendritic protein is primarily necessary for the induction of hippocampal CA1 DHPG-LTD because its induction can be blocked by translation inhibitors (Huber et al., 2000, 2001). To explore the possible contribution of mRNA translation to the DHPG-DEP, we performed a series of experiments in which we analyzed the effect of two translation inhibitors, cycloheximide and anisomycin, on the development of DHPG-DEP. As expected, preincubation of the hippocampal slices in the cycloheximide $(60 \mu \mathrm{M})$ for $30-60$ min blocked the induction of DHPG-DEP (Fig. 9A). The mean residual measured $40 \mathrm{~min}$ after washout of DHPG was $155 \pm$ $12 \%(n=6 ; p<0.05$ when compared with control DHPG-DEP slices; unpaired Student's $t$ test) of baseline (Fig. 9B). In addition, pretreatment of anisomycin $(20 \mu \mathrm{M})$ for $1 \mathrm{hr}$ also prevented the induction of DHPG-DEP (Fig. 9C). In anisomycin pretreatment slices, the mean residual measured $40 \mathrm{~min}$ after washout of DHPG was $145 \pm 13 \%(n=6 ; p<0.05$ when compared with control DHPG-DEP slices; unpaired Student's $t$ test) of baseline (Fig. 9D). In contrast, the induction of LTP was not significantly affected by either cycloheximide or anisomycin pretreatment. The slope of fEPSP measured 50 min after LTP induction was $155 \pm$ $11 \%$ ( $n=5 ; p>0.05$ when compared with control LTP slices; unpaired Student's $t$ test $)$ and $151 \pm 10 \%(n=5 ; p>0.05$ when compared with control LTP slices; unpaired Student's $t$ test) of baseline, respectively) (Fig. 9B,D). To examine the possible contribution of mRNA synthesis to the DHPG-DEP, we examined the effect of transcription inhibitor actinomycin D on DHPG- 
Table 1. Effects of pharmacological agent treatments on DHPG-induced depotentiation at hippocampal CA1 synapses

\begin{tabular}{lrr} 
Drug treatment & LTP 50 min after TS & $\begin{array}{c}\text { The residual LTP 40 } \\
\text { washout of DHPG }\end{array}$ \\
\hline Control & $153 \pm 12 \%(n=8)^{*}$ & $105 \pm 10 \%(n=6)$ \\
Okadaic acid $(1 \mu \mathrm{M}$ for $2-4 \mathrm{hr})$ & $165 \pm 11 \%(n=5)^{*}$ & $112.7 \pm 8.6 \%(n=6)$ \\
Calyculin A $(1 \mu \mathrm{M}$ for $2-4 \mathrm{hr})$ & $162.6 \pm 9.1 \%(n=5)^{*}$ & $109.5 \pm 7.9 \%(n=6)$ \\
FK-506 $(10 \mu \mathrm{M}$ for $2-4 \mathrm{hr})$ & $152.3 \pm 9.4 \%(n=5)^{*}$ & $112.6 \pm 9.3 \%(n=5)$ \\
Cyclosporin A $(250 \mu \mathrm{M}$ for $2-4 \mathrm{hr})$ & $158.8 \pm 8.9 \%(n=6)^{*}$ & $116 \pm 11 \%(n=4)$
\end{tabular}

These data represent the percentage of baseline for fEPSP slope. Number of experiments is in parentheses.

*Significantly different from baseline (unpaired Student's $t$ test; $p<0.05$ ).

DEP. In contrast to the translation inhibitors, actinomycin D (25 $\mu \mathrm{M})$ pretreatment for 30-60 min had no effect on the development of either LTP or DHPG-DEP (Fig. 9E). On average, the residual potentiation measured $40 \mathrm{~min}$ after washout of DHPG was $107 \pm 10 \%(n=6 ; p>0.05$ when compared with control DHPG-DEP slices; unpaired Student's $t$ test) of baseline. Moreover, the fEPSP slope measured $50 \mathrm{~min}$ after LTP induction was $149 \pm 12 \%(n=5 ; p>0.05$ when compared with control LTP slices; unpaired Student's $t$ test) of baseline (Fig. $9 F$ ). Comparison of the effect of translation and transcription inhibitors on DHPG-DEP was summarized in Figure $9 G$, in which the magnitude of depression measured 40 min after washout of DHPG was calculated relative to the magnitude of LTP measured at $48 \mathrm{~min}$ from each experiments. As shown in Figure $9 G$, the induction of DHPG-DEP was specifically prevented by translation inhibitors. These results suggest that like DHPG-LTD, an mRNA translation signaling is required in the establishment of DHPG-DEP at Schaffer collateral-CA1 synapses.

A recent study has characterized a rapamycin-sensitive translational signaling pathway that regulates the translation of a specific subclass of mRNAs and contributes to late-phase LTP and BDNF-induced synaptic potentiation (Tang et al., 2002). We therefore conducted experiments to assess the possible involvement of the rapamycin-sensitive pathway in translationdependent DHPG-DEP. As shown in Figure 10 $\mathrm{A}$, application of rapamycin $(200 \mathrm{nM})$ alone failed to affect the LTP induction but effectively prevented the induction of DHPG-DEP. The slope of fEPSP measured 50 min after LTP induction was $148 \pm 13 \%(n=$ $5 ; p>0.05$ when compared with control slices; unpaired Student's $t$ test) of baseline. The residual potentiation measured $40 \mathrm{~min}$ after DHPG washout was $143 \pm 12 \%(n=5 ; p<0.05$ when compared with control DHPG-DEP slices; unpaired Student's $t$ test). In contrast, application of FK506, a drug that has a similar structure and can bind to the same FKBP12 receptor as rapamycin but does not inhibit the target of rapamycin (Raught et al., 2001), did not affect the magnitude of either LTP or DHPG-DEP (Fig. 10B, Table 1). These results demonstrate a role for rapamycin-sensitive mRNA translation signaling in the development of DHPG-DEP.

\section{Postsynaptic expression of DHPG-DEP}

We further characterized the location of DHPG-DEP expression (presynaptic or postsynaptic) by testing its effect on PPF. When the excitatory afferents to the central neurons are activated twice at intervals of tens of milliseconds between each stimulus, the response to the second stimulus is generally facilitated in relation to the initial stimulus. This phenomenon is called PPF and is attributed to an increase of the amount of transmitter release to the second stimulus (Zucker, 1989). Thus, manipulations that affect transmitter release may interact strongly with PPF. In agreement with previous studies (Manabe et al., 1993), we found that LTP expression at Schaffer collateral-CA1 synapses was not associated with a significant change in PPF. Although the reduction in PPF was significant during the initial minute after tetanic stimulation, there was no change in PPF during the stable expression of LTP. On average, the PPF ratio $50 \mathrm{~min}$ after LTP induction was $1.48 \pm 0.06$, which was not significantly different from that of the control baseline values $(1.54 \pm 0.05 ; n=6 ; p>0.05$; paired Student's $t$ test) (Fig. 11A). In DHPG-DEP slices, the acute response of DHPG was associated with an increase in PPF ratio from $1.52 \pm 0.06$ to $1.94 \pm 0.06(n=6 ; p<0.05$; paired Student's $t$ test $)$, but the resulting depotentiation had no change in PPF (Fig. 11B). The average PPF ratio measured 40 min after washout of DHPG was $1.55 \pm 0.05$, which was not significantly different from the baseline PPF ratio (1.52 $\pm 0.06 ; n=6 ; p>0.05$; paired Student's $t$ test). These results suggest that the expression of DHPG-DEP at Schaffer collateral-CA1 synapses is postsynaptic.

\section{DHPG-DEP is associated with a reduction in the surface expression of AMPA receptors}

Over recent years, evidence has accumulated that rapid changes in the surface expression of postsynaptic ionotropic glutamate receptors are responsible for the expression of long-term synaptic plasticity in the brain (Isaac et al., 1995; Liao et al., 1995; Hayashi et al., 2000; Carroll et al., 2001). In addition, a recent report indicates that expression of DHPG-LTD is associated with an internalization of both AMPA and NMDA receptors from the surface of hippocampal neurons (Snyder et al., 2001). We therefore examined the effect of DHPG-DEP on the surface expression of AMPA receptors. To examine membrane surface expression of AMPA receptors, we adapted a biochemical surface biotinylation technique commonly used in cultured cells for use in the hippocampal slices (Chung et al., 2000; Snyder et al., 2001). Figure 12 shows that a substantial increase in surface expression of AMPA receptors is evident in LTP-established slices (128.5 \pm $5.5 \%$ of control slices; $n=6 ; p<0.05$ when compared with the control slices; paired Student's $t$ test). This result is consistent with that reported by other investigators (Shi et al., 1999; Hayashi et al., 2000). In DHPG-DEP slices, we found that there was a significant reduction of surface expression of AMPA receptors $(105.8 \pm 3.6 \%$ of control slices; $n=7 ; p<0.05$ when compared with the LTP slices; paired Student's $t$ test). However, application of DHPG alone without previous LTP induction also did not cause a significant reduction of surface expression of AMPA receptors $(96.9 \pm 4.5 \%$ of control slices; $n=6 ; p>0.05$ when compared with the control slices; paired Student's $t$ test). These results strongly support the notion that the expression of DHPG- 

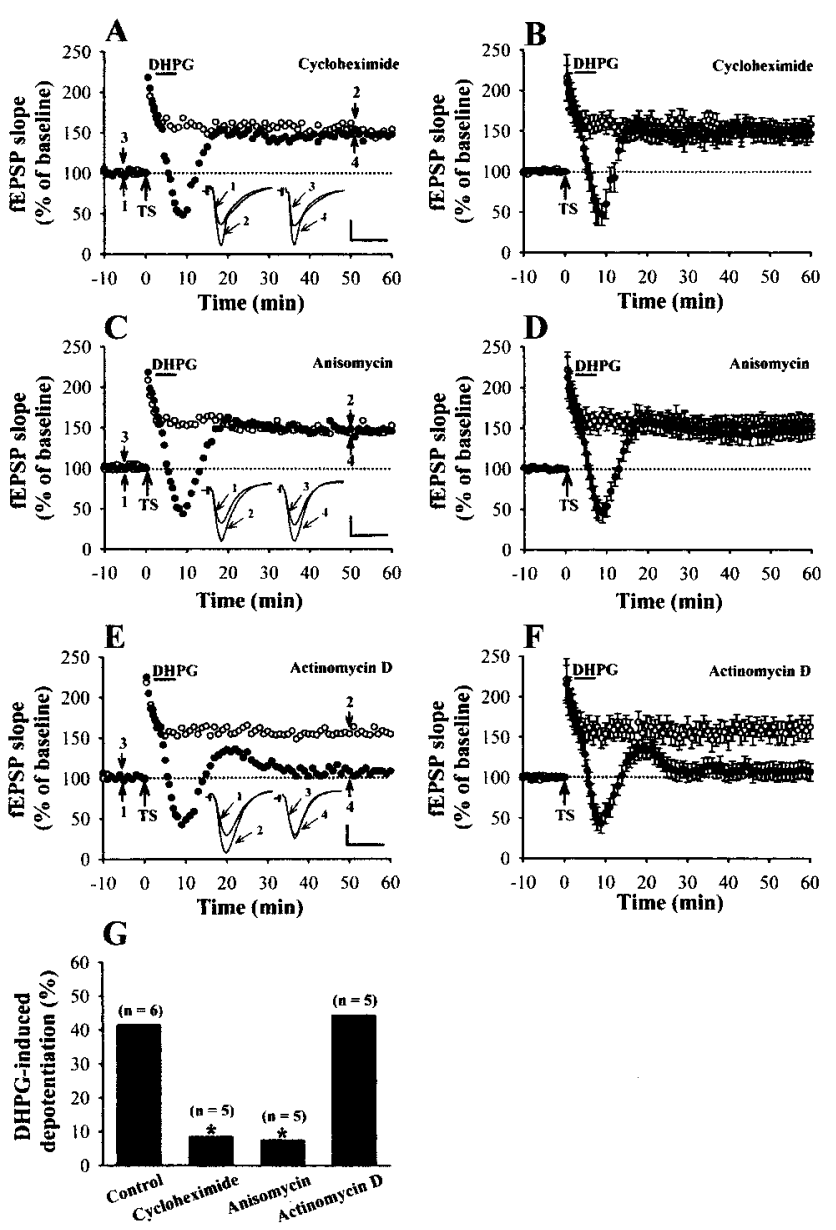

Figure 9. DHPG-DEP is dependent on protein synthesis but not mRNA synthesis. $A$, Example of experiments showing that preincubation of slices with the protein synthesis inhibitor cycloheximide $(60 \mu \mathrm{M} ; 30-60 \mathrm{~min})$ blocked the induction of DHPG-DEP but not LTP. $B$, Summary of data from experiments performed as in $A$ (LTP, $n=5$; DHPG-DEP, $n=6$ ). $C$, Example of experiments showing that preincubation of slices with another protein synthesis inhibitor, anisomycin $(20 \mu \mathrm{M} ; 1 \mathrm{hr})$, also blocked the induction of DHPG-DEP $(n=6)$ but not LTP $(n=5)$. $D$, Summary of data from experiments performed as in $C$ (LTP, $n=5$; DHPG-DEP, $n=6$ ). E, Example of experiments showing that preincubation of slices with the transcription inhibitor actinomycin D $(25 \mu \mathrm{M}$; $30-60 \mathrm{~min})$ had no effect on the induction of either DHPG-DEP $(n=6)$ or LTP $(n=5) . F$, Summary of data from experiments performed as in $E$ (LTP, $n=5$; DHPG-DEP, $n=6$ ). $G$, Histogram comparing the effect of transcription and translation inhibitors on the DHPG-DEP. Asterisks represent a significant difference from control group $(p<0.05)$. The magnitude of depotentiation was calculated by comparing the synaptic response at $40 \mathrm{~min}$ after washout of DHPG from the experiments illustrated in $B, D$, and $F$ with the magnitude of LTP at 48 min from the experiments illustrated in $B, D$, and $F$. Because both sets of data have variance, it is not possible to calculate an SE of these depotentiation values. The superimposed fEPSP in the inset illustrates respective recordings from example experiments taken at the time indicated by number. Horizontal bars denote the period of the delivery of DHPG. Calibration: $0.5 \mathrm{mV}, 10 \mathrm{msec}$.

DEP is attributable to a reversal of LTP-associated increase in the surface expression of AMPA receptors.

\section{Synaptic release of glutamate activates mGluR5 to reverse LTP}

The results thus far were obtained with exogenous application of DHPG, and it is unclear whether the release of glutamate from
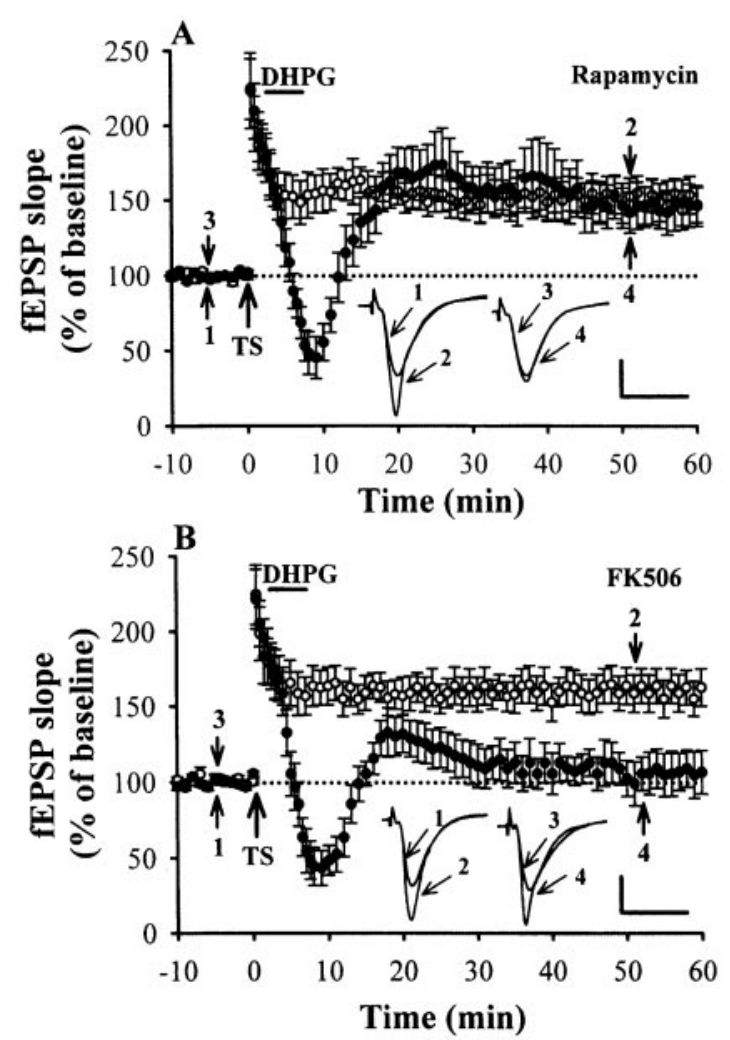

Figure 10. A rapamycin-sensitive signaling pathway contributes to DHPG-DEP. $A$, Summary of experiments showing that preincubation of slices with rapamycin (200 nM; 2-4 hr) blocked the induction of DHPGDEP $(n=5)$ but not LTP $(n=5)$. $B$, Summary of experiments showing that preincubation of slices with FK506 $(10 \mu \mathrm{M} ; 2-4 \mathrm{hr})$ did not affect either LTP $(n=5)$ or DHPG-DEP $(n=5)$. The superimposed fEPSP in the inset illustrates respective recordings from example experiments taken at the time indicated by number. Horizontal bars denote the period of the delivery of DHPG. Calibration: $0.5 \mathrm{mV}, 10 \mathrm{msec}$.

Schaffer collateral afferents can effectively activate mGluR5 to elicit depotentiation. In the final set of experiments, we adapted a recently reported protocol to test this hypothesis (Kemp and Bashir, 1999). As shown in Figure 13A, delivery of paired-pulse stimulation ( $50 \mathrm{msec}$ interstimulus interval) at $1 \mathrm{~Hz}$ for $15 \mathrm{~min}$ in the presence of D-APV $(50 \mu \mathrm{M})$ produced a stable form of LTD. The slope of fEPSP measured $30 \mathrm{~min}$ after PP-LFS was $77.9 \pm$ $7.6 \%(n=6 ; p<0.05$; unpaired Student's $t$ test $)$ of baseline. In these slices, no LTD was evoked in the presence of MPEP (10 $\mu \mathrm{M})$ during PP-LFS application. The slope of fEPSP measured 30 min after PP-LFS was $96.5 \pm 7.3 \%(n=6 ; p>0.05$; unpaired Student's $t$ test) of baseline (Fig. 13B). PP-LFS applied at $3 \mathrm{~min}$ after LTP induction, like DHPG application, completely reversed LTP (Fig. 13C). The mean residual potentiation measured $40 \mathrm{~min}$ after the end of PP-LFS was $107.2 \pm 8.4 \%(n=6)$ of baseline (Fig. 13D). Moreover, this PP-LFS-induced depotentiation was completely prevented by MPEP $(10 \mu \mathrm{M})$ during PP-LFS application (Fig. 13E). The mean residual potentiation measured $40 \mathrm{~min}$ after the end of PP-LFS was $158 \pm 12 \%$ ( $n=6$; $p<0.05$ when compared with PP-LFS-DEP slices; unpaired Student's $t$ test) of baseline (Fig. $13 F$ ). These results suggest that the long trains of paired-pulse stimulation of Schaffer collateral afferents that cause the synaptic release of glutamate are adequate to activate mGluR5 to trigger depotentiation. 

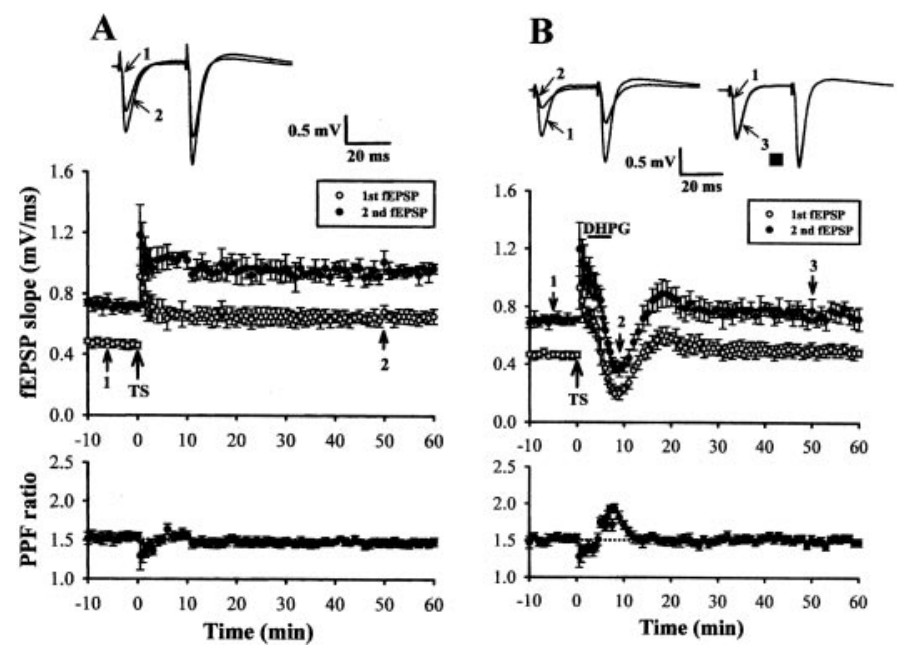

Figure 11. DHPG-DEP has no effect on PPF. A, Summary of six experiments showing that the expression of LTP was not associated with any change in PPF. $B$, Summary of six experiments showing that the expression of DHPG-DEP was also not associated with any change in PPF, although the acute synaptic depression was accompanied by a significant increase in PPF. The superimposed fEPSP in the top portion illustrates respective recordings from example experiments taken at the time indicated by number. Horizontal bars denote the period of the delivery of DHPG.
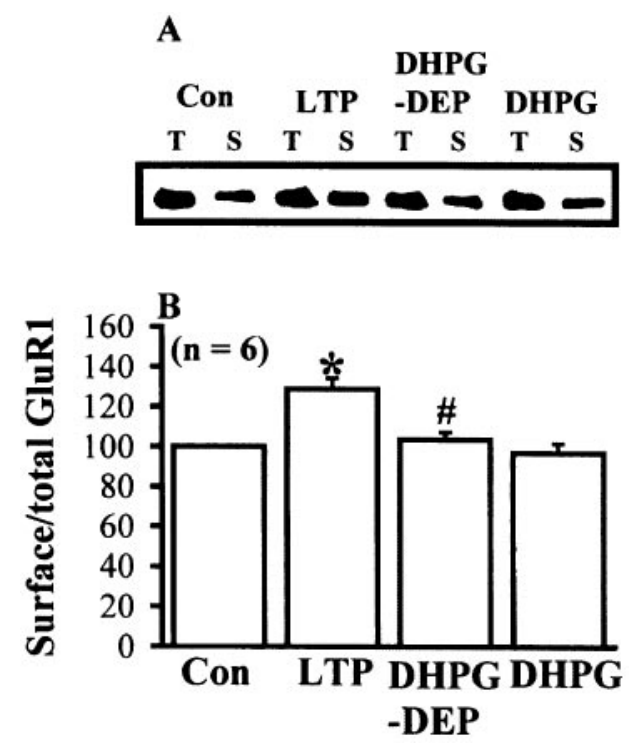

Figure 12. DHPG-DEP is accompanied by a loss of surface GluR1. A, Representative blot showing the total and biotinylated surface GluR1 from control (Con), LTP, DHPG-DEP, and DHPG treatment slices. B, Densitometric quantification revealed the change in surface GluR1 levels after LTP, DHPG-DEP, and DHPG treatment $(n=6)$. Note that the expression of DHPG-DEP is associated with a reduction in the increase of the surface expression of GluR1 seen with LTP. ${ }^{*} p<0.05$ when compared with the control slices; ${ }^{\#} p<0.05$ when compared with the LTP slices.

\section{DISCUSSION}

In the present study, we have shown that activation of mGluR5, either by a brief application of the selective group I mGluR agonist DHPG or with synaptically released glutamate (PP-LFS), can trigger a novel form of DEP by a mechanism that requires a de novo protein synthesis from existing mRNA. This mGluR5mediated depotentiation is (1) reversible, (2) able to unsaturate LTP, (3) time dependent, (4) induced postsynaptically, (5) mech-
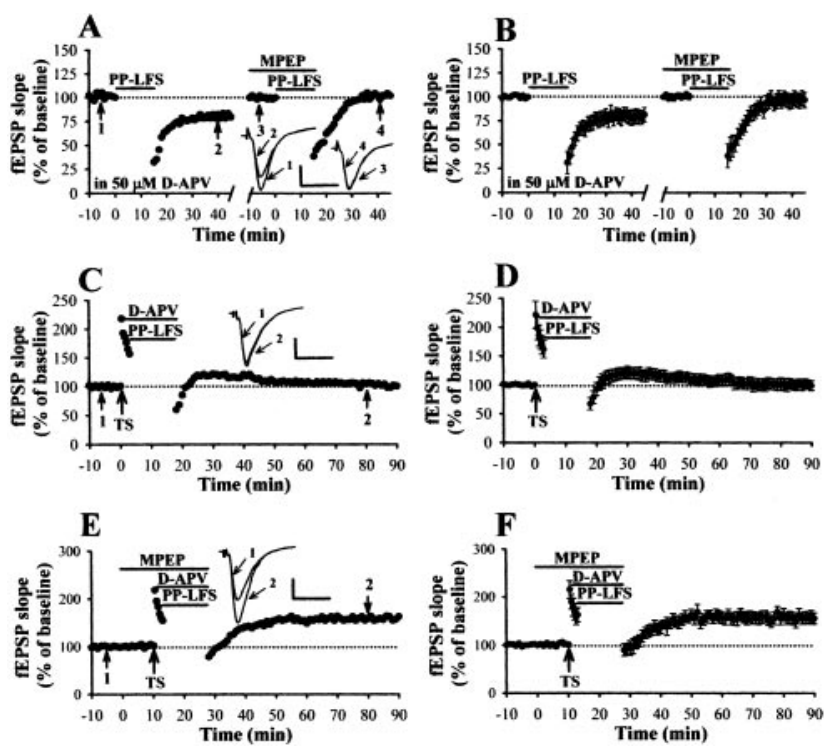

Figure 13. Paired-pulse low-frequency stimulation $(P P-L F S)$ induces mGluR5-dependent LTD and depotentiation. $A$, Example of an experiment showing that delivery of PPF-LFS (50 msec interstimulus interval; $1 \mathrm{~Hz} / 15 \mathrm{~min})$ in the presence of D-APV $(50 \mu \mathrm{M})$ produced a stable form of LTD at naive synapses. Pretreatment of the slices with the mGluR5 antagonist MPEP $(10 \mu \mathrm{M})$ blocked the induction of LTD with PP-LFS. $B$, Summary of data from six experiments performed as in $A$. $C$, Example of an experiment showing that PP-LFS can induce depotentiation at previous potentiated synapses in the presence of D-APV $(25 \mu \mathrm{M})$. $D$, Summary of data from six experiments performed as in $C$. E. Example of an experiment showing that PP-LFS-induced depotentiation was completely prevented by MPEP $(10 \mu \mathrm{M})$ during PP-LFS application. $F$, Summary of data from six experiments performed as in $E$. The superimposed fEPSP in the inset illustrates respective recordings from example experiments taken at the time indicated by number. Horizontal bars denote the period of the delivery of PP-LFS, D-APV, or MPEP. Calibration: $0.5 \mathrm{mV}, 10 \mathrm{msec}$.

anistically distinct from NMDAR-DEP, (6) independent of PLC signaling, and (7) not associated with PP activation. In addition, the expression of DHPG-DEP is caused, at least partly, by a rapid removal of AMPA receptors from the postsynaptic membrane.

In addressing the locus of expression of synaptic plasticity, a change in PPF is frequently used as an indication of presynaptic expression. As in the case for CA1 LTP (Manabe et al., 1993), the expression of DHPG-DEP caused no significant change in PPF (Fig. 11), which strongly suggests that DHPG-DEP is attributed to postsynaptic mechanisms. However, a recent report by Watabe et al. (2002) showed that a combination of postsynaptic induction and presynaptic expression is involved in DHPG-LTD in the hippocampal CA1 region. The reason that we do not observe the involvement of a presynaptic mechanism in the expression of DHPG-DEP is not clear but could be attributable partly to the use of different doses (10 vs $100 \mu \mathrm{M})$ and time scales of DHPG challenges (5 vs $10 \mathrm{~min}$ ), resulting in activation of different cellular processes that may vary in their mode of action. In contrast, the DHPG-induced acute depression of synaptic transmission is expressed presynaptically, because this depression was accompanied by a marked increase in PPF. Although it is difficult, on the basis of the present data, to estimate how DHPG acts presynaptically to reduce transmitter release and acts postsynaptically to induce DEP, a plausible explanation of this finding may be that DHPG acts on a different subtype of group I mGluRs to regulate CA1 pyramidal cell function. This idea is supported by the finding that the induction of DHPG-DEP was specifically 
blocked by the mGluR5 antagonist MPEP but not by mGluR1 antagonist LY367385 (Fig. 6), although both MPEP and LY367385 can partially inhibit the DHPG-induced acute synaptic depression. Taking all of these results together, we conclude that DHPG acts on postsynaptic mGluR5 to induce DEP and acts on presynaptic mGluR1 to reduce transmitter release. These observations are in agreement with recent anatomy data demonstrating that mGluR5 is the most abundant group I mGluR in CA1 pyramidal cells, whereas mGluR1 is not detectable (Baude et al., 1993; Romano et al., 1995).

How might mGluR5 activation lead to DEP? Although it is known that mGluR5 couples to PLC and therefore can activate PKC and mobilize $\mathrm{Ca}^{2+}$ from intracellular stores (Anwyl, 1999), it is unlikely that this conventional signal transduction mechanism underlies DHPG-DEP. Indeed, we could not inhibit the induction of DHPG-DEP by applying PLC blocker U73122 (Fig. 8). It appears, however, that a novel protein synthesis signaling pathway is involved in the induction of DHPG-DEP. Evidence supporting this is that preincubation of the hippocampal slices with the protein synthesis inhibitors, cycloheximide or anisomycin, but not the transcriptional inhibitor, actinomycin D, effectively prevents the induction of DHPG-DEP (Fig. 9). Such a result is in line with the observation that new protein synthesis is stimulated by group I mGluR activation in hippocampal synaptoneurosomes (Weiler et al., 1997; Angenstein et al., 1998). Recent studies have also demonstrated that rapid dendritic protein synthesis is required for the induction of DHPG-LTD (Huber et al., 2000, 2001) or DHPG-mediated facilitation of the persistence of an intermediate phase of LTP (Raymond et al., 2000) in the CA1 region of hippocampal slices. Although the signal transduction events that couple mGluR5 activation to protein synthesis control were not examined here, a rapamycin-sensitive signaling pathway seems to contribute to this process, because disruption of this signaling pathway with rapamycin inhibits the expression of DHPG-DEP (Fig. 10). Although a number of rapamycin-sensitive gene transcripts have been characterized to date, including those encoding ribosomal proteins (S3, S6, S14, and S24), translation initiation factors (eIF-4E, 4E-BP1, and 4E-BP2), and translation elongation factors (eEF1A and eEF2) (Brown and Schreiber, 1996; Raught et al., 2001; Steward and Schuman, 2001; Tang et al., 2002), the specific component of this signaling pathway participating in the development of DHPG-DEP remains to be established.

Activity-dependent changes in AMPA receptor trafficking have been proposed recently to play an important role in bidirectional synaptic plasticity (Malinow et al., 2000; Carroll et al., 2001). For example, it has been known that LTP induction in hippocampal slices is associated with an increase in the delivery of AMPA receptors to dendritic spines (Shi et al., 1999, 2001; Hayashi et al., 2000), whereas the expression of LTD is associated with a decrease in the surface expression of AMPA receptors (Kandler et al., 1998; Luthi et al., 1999). In addition, with the use of biochemical analysis, we have extended these findings by showing that the expression of DHPG-DEP is associated with a reduction in the increase of the surface expression of AMPA receptors seen with LTP (Fig. 12). This finding clearly indicates that removal of synaptic AMPA receptors is a candidate mechanism for the expression of DHPG-DEP in the hippocampus. Similarly, it has been found that cerebellar (Wang and Linden, 2000) and hippocampal CA1 (Snyder et al., 2001) LTD, which are also triggered by activation of group I mGluRs, require postsynaptic internalization of AMPA receptors. What mechanism might give rise to the removal of AMPA receptors from synapses during DHPG-DEP? Calcineurin (PP2B) was found to be involved in promoting AMPA receptor endocytosis in response to application of insulin (Lin et al., 2000) or AMPA (Beattie et al., 2000), suggesting that this signaling pathway might be widely involved in the internalization of AMPA receptors. However, we found that DHPG still induced depotentiation by applying the selective PP2B inhibitors, FK506 and cyclosporin A (Fig. 10, Table 1), indicating that this calcineurin-dependent signaling pathway is not involved in DHPG-mediated regulation of AMPA receptor endocytosis in the hippocampal slices. Furthermore, previous work has reported that PP1/2A inhibitors, okadaic acid and calyculin A, can facilitate DHPG-LTD in the hippocampal CA1 region (Schnabel et al., 2001), suggesting that PP1/2A might have an important, active role in governing the processes underlying DHPG-LTD. However, we found that neither okadaic acid nor calyculin A treatment significantly influences DHPG-DEP. This result argues that a $\mathrm{PP} 1 / 2 \mathrm{~A}$-dependent signaling process is involved in the generation of DHPG-DEP. The basis for the difference in the present results and those of Schnabel et al. (2001) is uncertain. However, it is unlikely that our treatment protocols were ineffective in blocking PP1/2A activity because the same treatment protocols used in our previous studies are found to be sufficient to prevent the LFS-induced DEP at the same synapses (Huang et al., 1999, 2001).

One of the intriguing aspects of DEP is that the magnitude of DEP is inversely proportional to the time lag of depotentiating stimulation after LTP induction (Fujii et al., 1991; O'Dell and Kandel, 1994). For example, we have reported previously that LFS can erase potentiation when delivered within 3 min after LTP induction, but it is without effect if administrated $10 \mathrm{~min}$ later (Huang et al., 1999). Here, we have extended these findings by showing that the reversal of LTP by DHPG was also primarily time dependent. These findings have led to a general belief that the biochemical processes that contribute to convert the initial potentiation into a persistent and not readily disrupted state require a period of time to reach completion.

Although a number of different protocols have been introduced to induce DEP, the most commonly studied forms of DEP are induced by prolonged LFS (LFS-DEP) and require the activation of postsynaptic NMDA receptors (Huang and Hsu, 2001). Although LFS-DEP and DHPG-DEP are superficially similar in that they are time dependent, are reversible, have the ability to unsaturate previously established LTP, and are induced postsynaptically, the mechanisms responsible for their induction and expression are very different. For example, LFS-DEP is dependent on the activation of both NMDA and $A_{1}$ adenosine receptors, whereas DHPG-DEP is dependent on mGluR5 activation. In addition, unlike LFS-DEP, DHPG-DEP does not require any electrical stimulation of the presynaptic terminal for its induction and does not require the activation of a protein phosphatasecoupled signaling pathway (Table 1 ). Moreover, a rapid postsynaptic protein synthesis is required for the induction of DHPGDEP but not LFS-DEP. Taken together, the above findings favor the assumption that LFS-DEP and DHPG-DEP are two mechanistically distinct forms of synaptic plasticity, although these two forms of DEP may coexist at the same synapses.

In conclusion, we have shown that selective activation of group I mGluRs, and of mGluR5 in particular, induces a novel form of DEP. This DHPG-DEP is mechanistically distinct from previously reported forms of hippocampal CA1 DEP evoked under identical conditions and is expressed via a protein synthesis-dependent 
change of the postsynaptic AMPA receptor expression. This DHPG-DEP model may be useful for dissecting the functional role of DEP in the information storage of the mammalian brain.

\section{REFERENCES}

Abraham WC, Bear MF (1996) Metaplasticity: the plasticity of synaptic plasticity. Trends Neurosci 19:126-130.

Angenstein F, Greenough WT, Weiler IJ (1998) Metabotropic glutamate receptor-initiated translocation of protein kinase p90rsk to polyribosomes: a possible factor regulating synaptic protein synthesis. Proc Natl Acad Sci USA 95:15078-15083.

Anwyl R (1999) Metabotropic glutamate receptors: electrophysiological properties and role in plasticity. Brain Res Rev 29:83-120.

Arai A, Kessler M, Lynch G (1990) The effect of adenosine on the development of long-term potentiation. Neurosci Lett 119:41-44.

Bahr BA, Stäubli U, Xiao P, Chun D, Ji ZX, Esteban ET, Lynch G (1997) Arg-Gly-Asp-Ser-selective adhesion and the stabilization of long-term potentiation: pharmacological studies and the characterization of a candidate matrix receptor. J Neurosci 17:1320-1329.

Barrionuevo G, Schottler F, Lynch G (1980) The effect of repetitive low frequency stimulation on control and "potentiated" responses in the hippocampus. Life Sci 27:2385-2391.

Baude A, Nusser Z, Roberts JD, Mulvihill E, McIlhinney RA, Somogyi $\mathrm{P}(1993)$ The metabotropic glutamate receptor (mGluR1 $\alpha$ ) is concentrated at perisynaptic membrane of neuronal subpopulations as detected by immunogold reaction. Neuron 11:771-787.

Beattie EC, Carroll RC, Yu X, Morishita W, Yasuda H, von Zastrow M, Malenka RC (2000) Regulation of AMPA receptor endocytosis by a signaling mechanism shared with LTD. Nat Neurosci 3:1291-1300.

Bliss TV, Lømo T (1973) Long-lasting potentiation of synaptic transmission in the dentate area of the anaesthetized rabbit following stimulation of the perforant path. J Physiol (Lond) 232:331-356.

Bliss TVP, Collingridge GL (1993) A synaptic model of memory: longterm potentiation in the hippocampus. Nature 361:31-39.

Brown EJ, Schreiber SL (1996) A signaling pathway to translational control. Cell 86:517-520.

Carroll RC, Beattie EC, von Zastrow M, Malenka RC (2001) Role of AMPA receptor endocytosis in synaptic plasticity. Nat Rev Neurosci 2:315-324.

Chuang SC, Bianchi R, Kim D, Shin HS, Wong RK (2001) Group I metabotropic glutamate receptors elicit epileptiform discharges in the hippocampus through PLC $\beta 1$ signaling. J Neurosci 21:6387-6394.

Chung HJ, Xia J, Scannevin RH, Zhang X, Huganir RL (2000) Phosphorylation of the AMPA receptor subunit GluR2 differentially regulates its interaction with PDZ domain-containing proteins. J Neurosci 20:7258-7267.

Dudek SM, Bear MF (1993) Bidirectional long-term modification of synaptic effectiveness in the adult and immature hippocampus. J Neurosci 13:2910-2918.

Fujii S, Saito K, Miyakawa H, Ito K, Kato H (1991) Reversal of long-term potentiation (depotentiation) induced by tetanus stimulation of the input to CA1 neurons of guinea pig hippocampal slices. Brain Res 555:112-122.

Fujii S, Sekino Y, Kuroda Y, Sasaki H, Ito K, Kato H (1997) 8-Cyclopentyltheophylline, an adenosine A1 receptor antagonist, inhibits the reversal of long-term potentiation in hippocampal CA1 neurons. Eur J Pharmacol 331:9-14.

Hayashi Y, Shi SH, Esteban JA, Piccini A, Poncer JC, Malinow R (2000) Driving AMPA receptors into synapses by LTP and CaMKII: requirement for GluR1 and PDZ domain interaction. Science 287:2262-2267.

Huang CC, Hsu KS (2001) Progress in understanding the factors regulating the reversibility in long-term potentiation. Rev Neurosci 12:51-68.

Huang CC, Liang YC, Hsu KS (1999) A role for extracellular adenosine in time-dependent reversal of long-term potentiation by low-frequency stimulation at hippocampal CA1 synapses. J Neurosci 19:9728-9738.

Huang CC, Liang YC, Hsu KS (2001) Characterization of the mechanism underlying the reversal of long-term potentiation by low-frequency stimulation at hippocampal CA1 synapses. J Biol Chem 276:48108-48117.

Huber KM, Kayser MS, Bear MF (2000) Role for rapid dendritic protein synthesis in hippocampal mGluR-dependent long-term depression. Science 288:1254-1257.

Huber KM, Roder JC, Bear MF (2001) Chemical induction of mGluR5and protein synthesis-dependent long-term depression in hippocampal area CA1. J Neurophysiol 86:321-325.

Isaac JT, Nicoll RA, Malenka RC (1995) Evidence for silent synapses: implications for the expression of LTP. Neuron 15:427-434

Kandler K, Katz LC, Kauer JA (1998) Focal photolysis of caged glutamate produces long-term depression of hippocampal glutamate receptors. Nat Neurosci 1:119-123.

Kemp N, Bashir ZI (1999) Induction of LTD in the adult hippocampus by the synaptic activation of AMPA/kainate and metabotropic glutamate receptors. Neuropharmacology 38:495-504.

Larson J, Xiao P, Lynch G (1993) Reversal of LTP by theta frequency stimulation. Brain Res 600:97-102.
Liao D, Hessler NA, Malinow R (1995) Activation of postsynaptically silent synapses during pairing-induced LTP in CA1 region of hippocampal slice. Nature 375:400-404.

Lin JW, Ju W, Foster K, Lee SH, Ahmadian G, Wyszynski M, Wang YT, Sheng M (2000) Distinct molecular mechanisms and divergent endocytotic pathways of AMPA receptor internalization. Nat Neurosci 3:1282-1290.

Luthi A, Chittajallu R, Duprat F, Palmer MJ, Benke TA, Kidd FL, Henley JM, Isaac JT, Collingridge GL (1999) Hippocampal LTD expression involves a pool of AMPARs regulated by the NSF-GluR2 interaction. Neuron 24:389-399.

Malenka RC, Nicoll RA (1999) Long-term potentiation-a decade of progress? Science 285:1870-1874.

Malinow R, Mainen ZF, Hayashi Y (2000) LTP mechanisms: from silence to four-lane traffic. Curr Opin Neurobiol 10:352-357.

Manabe T, Wyllie DJA, Perkel DJ, Nicoll RA (1993) Modulation of synaptic transmission and long-term potentiation: effects on paired pulse facilitation and EPSC variance in the CA1 region of the hippocampus. J Neurophysiol 70:1451-1459.

Martin SJ, Grimwood PD, Morris RG (2000) Synaptic plasticity and memory: an evaluation of the hypothesis. Annu Rev Neurosci 23:649-711.

Mulkey RM, Malenka RC (1992) Mechanisms underlying induction of homosynaptic long-term depression in area CA1 of hippocampus. Neuron 9:967-975.

Mulkey RM, Herron CE, Malenka RC (1993) An essential role for protein phosphatases in hippocampal long-term depression. Science 261:1051-1055

O'Dell T, Kandel E (1994) Low-frequency stimulation erases LTP through an NMDA receptor-mediated activation of protein phosphatases. Learn Mem 1:129-139.

Palmer MJ, Irving AJ, Seabrook GR, Jane DE, Collingridge GL (1997) The group I mGlu receptor agonist DHPG induces a novel form of LTD in the CA1 region of the hippocampus. Neuropharmacology 36:1517-1532.

Pike FG, Goddard RS, Suckling JM, Ganter P, Kasthuri N, Paulsen O (2000) Distinct frequency preferences of different types of rat hippocampal neurones in response to oscillatory input currents. J Physiol (Lond) 529:205-213.

Raught B, Gingras AC, Sonenberg N (2001) The target of rapamycin (TOR) proteins. Proc Natl Acad Sci USA 98:7037-7044.

Raymond CR, Thompson VL, Tate WP, Abraham WC (2000) Metabotropic glutamate receptors trigger homosynaptic protein synthesis to prolong long-term potentiation. J Neurosci 20:969-976.

Romano C, Sesma MA, McDonald CT, O’Malley K, Van den Pol AN, Olney JW (1995) Distribution of metabotropic glutamate receptor mGluR5 immunoreactivity in rat brain. J Comp Neurol 355:4554-4569.

Sanes JR, Lichtman JW (1999) Can molecules explain long-term otentiation? Nat Neurosci 2:597-604.

Schnabel R, Kilpatrick IC, Collingridge GL (2001) Protein phosphatase inhibitors facilitate DHPG-induced LTD in the CA1 region of the hippocampus. Br J Pharmacol 132:1095-1101.

Shi S, Hayashi Y, Esteban JA, Malinow R (2001) Subunit-specific rules governing AMPA receptor trafficking to synapses in hippocampal pyramidal neurons. Cell 105:331-343.

Shi SH, Hayashi Y, Petralia RS, Zaman SH, Wenthold RJ, Svoboda K, Malinow R (1999) Rapid spine delivery and redistribution of AMPA receptors after synaptic NMDA receptor activation. Science 284:18111816.

Snyder EM, Philpot BD, Huber KM, Dong X, Fallon JR, Bear MF (2001) Internalization of ionotropic glutamate receptors in response to mGluR activation. Nat Neurosci 4:1079-1085.

Stäubli U, Chun D (1996) Factors regulating the reversibility of longterm potentiation. J Neurosci 16:853-860.

Stäubli U, Chun D, Lynch G (1998) Time-dependent reversal of longterm potentiation by an integrin antagonist. J Neurosci 8:3460-3469.

Steward O, Schuman EM (2001) Protein synthesis at synaptic sites on dendrites. Annu Rev Neurosci 24:299-325.

Tang SJ, Reis G, Kang H, Gingras AC, Sonenberg N, Schuman EM (2002) A rapamycin-sensitive signaling pathway contributes to longterm synaptic plasticity in the hippocampus. Proc Natl Acad Sci USA 99:467-472.

Wagner JJ, Alger BE (1996) Homosynaptic LTD and depotentiation: do they differ in name only? Hippocampus 6:24-29.

Wang YT, Linden DJ (2000) Expression of cerebellar long-term depression requires postsynaptic clathrin-mediated endocytosis. Neuron 25:635-647.

Watabe AM, Carlisle HJ, O'Dell TJ (2002) Postsynaptic induction and presynaptic expression of group 1 mGluR-dependent LTD in the hippocampal CA1 region. J Neurophysiol 87:1395-1403.

Weiler IJ, Irwin SA, Klintsova AY, Spencer CM, Brazelton AD, Miyashiro K, Comery TA, Patel B, Eberwine J, Greenough WT (1997) Fragile X mental retardation protein is translated near synapses in response to neurotransmitter activation. Proc Natl Acad Sci USA 94:5395-5400.

Zucker RS (1989) Short-term synaptic plasticity. Annu Rev Neurosci 12:13-31. 